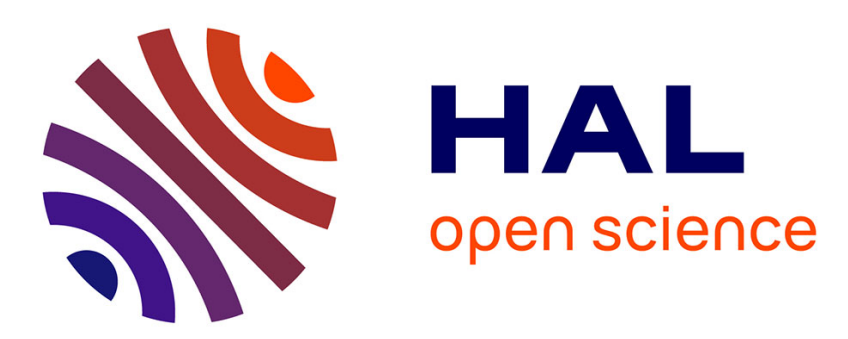

\title{
Ion collision cross sections with transport and reaction coefficients in Ar, Cl2 and N2 and their mixtures for photonic crystal applications
}

A Hennad, Mohammed Yousfi

\section{- To cite this version:}

A Hennad, Mohammed Yousfi. Ion collision cross sections with transport and reaction coefficients in Ar, Cl2 and N2 and their mixtures for photonic crystal applications. Journal of Physics D: Applied Physics, 2011, 44 (2), pp.25201. 10.1088/0022-3727/44/2/025201 . hal-00597850

\author{
HAL Id: hal-00597850 \\ https://hal.science/hal-00597850
}

Submitted on 2 Jun 2011

HAL is a multi-disciplinary open access archive for the deposit and dissemination of scientific research documents, whether they are published or not. The documents may come from teaching and research institutions in France or abroad, or from public or private research centers.
L'archive ouverte pluridisciplinaire HAL, est destinée au dépôt et à la diffusion de documents scientifiques de niveau recherche, publiés ou non, émanant des établissements d'enseignement et de recherche français ou étrangers, des laboratoires publics ou privés. 


\section{Title:}

Ion collision cross sections with transport and reaction coefficients in $\mathrm{Ar}, \mathrm{Cl}_{2}$ and $\mathrm{N}_{2}$ and their mixtures for photonic crystal applications

$$
\text { A. Hennad*, M. Yousfi }{ }^{* *}
$$

\section{Adresses:}

*Université des Sciences et de la Technologie d'Oran Mohamed Boudiaf, USTO-MB, ETTLMSE, BP 1505 El M’Naouer, 31000 Oran, Algeria

***niversité de Toulouse, Laplace, UMR CNRS 5213, UPS, 118 Route de Narbonne, 31062 Toulouse, France

\section{Corresponding author:}

Dr M. Yousfi, Université de Toulouse, Laplace, UMR CNRS 5213, UPS, 118 Route de Narbonne, 31062 Toulouse, France

Email: yousfi@laplace.univ-tlse.fr

PACS numbers(s): 52.20.Hv, 51.50.+v, 52.25.Fi

\section{$\underline{\text { Abstract : }}$}

The ion swarm transport coefficients such as reduced mobility, diffusion coefficients and reaction rates of the following systems $\mathrm{Ar}^{+} / \mathrm{Cl}_{2}, \mathrm{Ar}^{+} / \mathrm{N}_{2}, \mathrm{~N}_{2}{ }^{+} / \mathrm{Cl}_{2}$ and $\mathrm{N}_{2}{ }^{+} / \mathrm{Ar}$ have been determined from a Monte Carlo simulation using calculated elastic and experimentally estimated inelastic collision cross sections. The elastic momentum transfer cross sections have been determined from a semi-classical JWKB approximation based on a rigid core interaction potential model. The inelastic cross sections have been fitted using the measured reaction coefficients as for instance ion conversion reaction coefficients. Then, the cross sections sets are fitted using either the measured reduced mobility when available in the literature or the zero-field mobility calculated from the Satoh's relation. From the sets of elastic and inelastic collision cross sections thus obtained in $\mathrm{Ar}^{+} / \mathrm{Cl}_{2}, \mathrm{Ar}^{+} / \mathrm{N}_{2}, \mathrm{~N}_{2}{ }^{+} / \mathrm{Cl}_{2}$ and $\mathrm{N}_{2}^{+} /$Ar systems, the ion transport and reaction coefficients are then calculated in pure gases and also in binary and ternary mixtures involving $\mathrm{Cl}_{2}$, Ar and $\mathrm{N}_{2}$ over a wide range of reduced electric field. These ion data are very useful for modelling and simulation of non equilibrium low pressure electrical discharges used more particularly for etching of the III-V compounds in the case of crystal photonic applications. 


\section{Introduction:}

In the frame work of photonic crystal applications, inductively coupled plasmas (ICP) in chlorine gas mixtures $\left(\mathrm{Cl}_{2} / \mathrm{Ar}, \mathrm{Cl}_{2} / \mathrm{N}_{2}, \mathrm{Cl}_{2} / \mathrm{H}_{2}\right.$, etc.) are very promising candidates for etching the III-V compounds. The presence of $\mathrm{Cl}_{2}$ in the mixture favours the volatility of chloride species formed during plasma etching while the presence of $\mathrm{N}_{2}$ increases the anisotropy of the etching and removes the roughness of the hole surfaces (see for instance Refs [1] up [4] and the references given therein).

Furthermore, ICP sources are able to generate high ion fluxes with an ion energy controlled thanks to the bias potential of the substrate holder thus leading to operating parameters very favourable to a high etching velocity. In order to better understand the plasma formation and its stability in presence of negative chlorine ion and also to optimise the positive ion flux arriving to the etched surface, the experimental investigations have to be completed by discharge modelling. The electrodynamics and kinetics discharge modelling needs more particularly a good knowledge of ion collision cross sections and also transport and reaction coefficients in the chlorine mixtures used in photonic crystal applications. In the literature there are some compilations on ion data as for instance those of Ellis et al (refs [5]) or Viehland [6] or more recently Petrovic et al [7] on negative ion for nanotechnology applications, Nelson et al [8] for ion in air and flue gases and Yousfi et al [9] on ions in gas mixtures for PECVD thin film deposition. However, in the gas mixtures of our interest involving chlorine, ion data are very sparse more particularly in the case of ions interacting with their non parent gases. In fact, ion collision cross sections are available in the literature only in the case of ion interacting with their parent species as for instance in the case $\mathrm{Ar}^{+} / \mathrm{Ar}$ [10] or $\mathrm{N}_{2}^{+} / \mathrm{N}_{2}[11]$.

For binary or ternary mixture involving $\mathrm{Cl}_{2}$, $\mathrm{Ar}$ and $\mathrm{N}_{2}$, several ions can be formed in the low pressure discharges of our interest as for example $\mathrm{Ar}^{+}, \mathrm{N}_{2}{ }^{+}, \mathrm{N}^{+}, \mathrm{Cl}^{-}, \mathrm{Cl}_{2}{ }^{+}$and $\mathrm{Cl}^{+}$(see e.g. [12]). Obviously, the transport and the interactions of such ions with the neutral gas mixture directly affect the electro-dynamics and the reactivity of the ICP discharge and therefore its etching efficiency. So, the aim of our first work in these chlorine mixtures is to give the collision cross sections of $\mathrm{Ar}^{+}$and $\mathrm{N}_{2}{ }^{+}$interacting either with $\mathrm{Cl}_{2}$, or $\mathrm{Ar}$ or $\mathrm{N}_{2}$. These concern more particularly the systems $\mathrm{Ar}^{+} / \mathrm{Cl}_{2}, \mathrm{Ar}^{+} / \mathrm{N}_{2}, \mathrm{~N}_{2}{ }^{+} / \mathrm{Cl}_{2}$ and $\mathrm{N}_{2}{ }^{+} / \mathrm{Ar}$ whose the cross sections are not available in the literature.

The calculation method of elastic momentum transfer cross section based on JWKB approximation using a rigid core interaction potential model is given in section 2 with the choice of inelastic cross sections. An optimized Monte Carlo method [13] is used for the fitting of the collision cross sections from comparison with measured mobility data or Satoh's relation [14] in the case of elastic processes and from comparison with measured reaction coefficients in the case of inelastic processes. In section 3, from the present fitted sets of elastic and inelastic collision cross sections of $\mathrm{Ar}^{+}$and $\mathrm{N}_{2}{ }^{+}$in their non parent gases $\left(\mathrm{Ar}, \mathrm{Cl}_{2}\right.$ and $\mathrm{N}_{2}$ ) and from the literature (refs [10] and [11]) sets in the case of these ions in their parent gases $\left(\mathrm{Ar}^{+} / \mathrm{Ar}\right.$ and $\left.\mathrm{N}_{2}^{+} / \mathrm{N}_{2}\right)$, the ion transport and reaction coefficients are calculated and analysed over a wide range of reduced electric field $\mathrm{E} / \mathrm{N}$ in binary and ternary mixtures including $\mathrm{Cl}_{2}$, Ar and $\mathrm{N}_{2}$ used as gas mixture filling inside ICP reactor for crystal photonic applications.

\section{$\underline{\text { 2. Method of calculation and analysis of collision cross sections }}$}

\subsection{Method of calculation}

The ion transport and reaction coefficients are calculated from an optimized Monte Carlo method well adapted to both symmetric and asymmetric ion/gas system [13]. This needs as 
input data both elastic and inelastic collision cross sections. The elastic momentum transfer cross section has been calculated using a semi classical formalism based on JWKB approximation for the phase shift using a rigid core potential model describing the ion/molecule interaction [15]:

$$
V(r)=\frac{n \varepsilon_{m}}{3 n-12}\left\{\frac{12}{n}\left(\frac{r_{m}-a}{r-a}\right)^{n}-3\left(\frac{r_{m}-a}{r-a}\right)^{4}\right\}
$$

$r$ is the intermolecular distance, $\varepsilon_{m}$ the minimum energy of the potential, $r_{m}$ the position of the minimum, $n$ is the power of the repulsive part of the potential and $a$ is the shift between the mass and the charge centres.

In the framework of JWKB approximation, the phase shift $\delta_{l}$ using depends on impact parameter $b$ and interaction potential $V(r)$ as following:

$$
\delta_{l} \approx \delta(b)=k \int_{r_{c}}^{\infty}\left(1-\frac{b^{2}}{r^{2}}-\frac{V(r)}{\varepsilon_{r}}\right)^{1 / 2} d r-k \int_{b}^{\infty}\left(1-\frac{b^{2}}{r^{2}}\right)^{1 / 2} d r
$$

with $b=\frac{l+1 / 2}{k}$ where $l$ is the angular momentum quantum number, $b$ the impact parameter, and $k$ the wave number of the relative motion proportional to the ion/neutral relative energy $\varepsilon_{r}$

The elastic momentum transfer cross section $Q_{m}\left(\varepsilon_{r}\right)$ is calculated from :

$$
Q_{m}\left(\varepsilon_{r}\right)=\frac{4 \pi}{k^{2}} \sum_{l=0}^{\infty}(l+1) \sin ^{2}\left(\delta_{l+1}-\delta_{l}\right)
$$

Then, the inelastic cross sections have been either taken from literature or fitted using the available data on reaction coefficients.

The set of calculated elastic cross sections $Q_{m}$ and estimated inelastic cross sections in $\mathrm{Ar}^{+} / \mathrm{Cl}_{2}, \mathrm{Ar}^{+} / \mathrm{N}_{2}, \mathrm{~N}_{2}^{+} / \mathrm{Cl}_{2}$, and $\mathrm{N}_{2}^{+} / \mathrm{Ar}$ are shown in figures 1 to 4 from thermal energy up to $100 \mathrm{eV}$. In the following, the literature information available in the studied systems $\mathrm{Ar}^{+} / \mathrm{Cl}_{2}$, $\mathrm{Ar}^{+} / \mathrm{N}_{2}, \mathrm{~N}_{2}^{+} / \mathrm{Cl}_{2}$, and $\mathrm{N}_{2}{ }^{+} / \mathrm{Ar}$ are given.

\section{2 $\mathrm{Ar}^{+}$and $\mathrm{N}_{2}^{+}$ions in pure $\mathrm{Ar}, \mathrm{Cl}_{2}$, and $\mathrm{N}_{2}$}

In the case of $\mathrm{Ar}^{+} / \mathrm{Cl}_{2}$, according to the literature, the most probable collision processes in the energy range of our interest are:

$$
\begin{aligned}
& \mathrm{Ar}^{+}+\mathrm{Cl}_{2} \longrightarrow \mathrm{Ar}^{+}+\mathrm{Cl}_{2} \\
& \mathrm{Ar}^{+}+\mathrm{Cl}_{2} \longrightarrow \mathrm{Cl}_{2}^{+}+\mathrm{Ar}+4.28 \mathrm{eV} \\
& \mathrm{Ar}^{+}+\mathrm{Cl}_{2} \longrightarrow \mathrm{Cl}^{+}+\mathrm{Cl}+\mathrm{Ar}+0.20 \mathrm{eV}
\end{aligned}
$$

Reaction (1) corresponds to the classic elastic collision with momentum transfer cross section $Q_{m}$ (see figure 1) while reaction (2) is a non resonant charge transfer. This exothermic reaction is observed by Murrel [16] and Spanel et al [17]. Reaction (3) is a dissociative charge transfer producing $\mathrm{Cl}^{+}$. According to Spanel et al., the ion production of $\mathrm{Cl}_{2}^{+}\left({ }^{2} \Sigma_{\mathrm{g}}^{+}\right)$or $\mathrm{Cl}_{2}^{+}\left({ }^{2} \Pi_{\mathrm{u}}\right)$ is the largest reaction (75\%). This total inelastic cross section $\mathrm{Q}\left(\mathrm{Cl}_{2}{ }^{+}, \mathrm{Cl}^{+}\right)$, corresponding to reactions (2) and (3) and shown in figure 1, is validated from the good agreement obtained between the measurement $\left(k_{i n}=1.49 \pm 0.5 \times 10^{-10} \mathrm{~cm}^{3} \mathrm{~s}^{-1}\right.$ Ikezoe and al. [18]) and the Monte Carlo calculations of the total non-resonant charge transfer rate $k_{i n}$. 
In the case of $\mathrm{Ar}^{+} / \mathrm{N}_{2}$ system, the most probable collision processes in the energy range our interest are:

$$
\begin{aligned}
& \mathrm{Ar}^{+}+\mathrm{N}_{2} \longrightarrow \mathrm{Ar}^{+}+\mathrm{N}_{2} \\
& \mathrm{Ar}^{+}+\mathrm{N}_{2} \longrightarrow \mathrm{N}_{2}^{+}+\mathrm{Ar}-0.07 \mathrm{eV} \\
& \mathrm{Ar}^{+}+\mathrm{N}_{2} \longrightarrow \mathrm{N}^{+}+\mathrm{N}+\mathrm{Ar}-8.53 \mathrm{eV} \\
& \mathrm{Ar}^{+}+\mathrm{N}_{2} \longrightarrow \mathrm{ArN}^{+}+\mathrm{N}-8.20 \mathrm{eV}
\end{aligned}
$$

Reaction (4) corresponds to the elastic momentum transfer cross section $Q_{m}$. Reaction (5) is a non-resonant charge transfer. The threshold and the collision cross section corresponding to reaction (5) are given in the literature (Viggiano and al. [19], Smith and Adams [20], Liao et al. [21], Liao et al [22], Flesch and $\mathrm{Ng}$ [23]). The total non-resonant transfer charge cross section $Q\left(N_{2}^{+}\right)$by $\operatorname{Ar}^{+}\left({ }^{2} \mathrm{P}_{3 / 2}\right)$ and $\operatorname{Ar}^{+}\left({ }^{2} \mathrm{P}_{1 / 2}\right)$ impacts is shown in figure 2 . This cross section is measured by Liao et al [22] and Flesch and $\mathrm{Ng}$ [23]. Reaction (6) leading to the production of $\mathrm{N}^{+}$is observed by Flesch and $\mathrm{Ng}$ ([23] and [24]) while reaction (7) corresponding to production $\mathrm{ArN}^{+}$has been detected by Flesch and $\mathrm{Ng}$ [23] and also Tosi et al. [25]. Concerning the magnitudes of the inelastic cross sections of reactions (5), (6) and (7), it is worth noting that reaction (5) is a largely dominant process in comparison to reactions (6) and (7). This is why the inelastic cross section of theses two later reactions have been neglected and not shown in figure 2 .

In the case of $\mathrm{N}_{2}{ }^{+} / \mathrm{Cl}_{2}$ system, in addition to the elastic collision (reaction 8), there is the non-resonant charge transfer (reaction 9).

$$
\begin{aligned}
& \mathrm{N}_{2}^{+}+\mathrm{Cl}_{2} \longrightarrow \mathrm{N}_{2}^{+}+\mathrm{Cl}_{2} \\
& \mathrm{~N}_{2}^{+}+\mathrm{Cl}_{2} \longrightarrow \mathrm{Cl}_{2}^{+}+\mathrm{N}_{2}+4.10 \mathrm{eV}
\end{aligned}
$$

Reaction (8) is characterized by its elastic momentum transfer collision cross section $Q_{m}$ shown in figure 3 with the inelastic cross section for asymmetric charge transfer reaction (9). This interaction is an exothermic process because the energy difference between the ionization potentials of $\mathrm{N}_{2}(15.58 \mathrm{eV})$ and $\mathrm{Cl}_{2}(11.48 \mathrm{eV})$ is positive and equal to $4.10 \mathrm{eV}$. This inelastic cross section $Q\left(\mathrm{Cl}_{2}^{+}\right)$corresponding to reaction (9) is validated from the good agreement obtained between the measurement $\left(k_{i n}=6.0 \times 10^{-10} \mathrm{~cm}^{3} \mathrm{~s}^{-1} \pm 20 \%\right.$ Anicich [26] $)$ and the Monte Carlo calculations of the non-resonant charge transfer rate coefficient.

In the case of $\mathrm{N}_{2}^{+} / \mathrm{Ar}$ system, the dominant interactions between $\mathrm{N}_{2}{ }^{+}$and Ar occurring in our energy range (thermal energy up to about $100 \mathrm{eV}$ ) are, respectively, the elastic momentum transfer cross section (reaction 10) ( $Q m$ in figure 4) and the non resonant charge transfer (reaction 11) $\left(Q\left(\mathrm{Ar}^{+}\right)\right.$in figure 4). In fact reaction (reaction 12) producing $\mathrm{ArN}^{+}$is also observed by Tosi et al [27] but has a much more lower magnitude cross section and therefore has been neglected.

$$
\begin{aligned}
& \mathrm{N}_{2}^{+}+\mathrm{Ar} \longrightarrow \mathrm{N}_{2}^{+}+\mathrm{Ar} \\
& \mathrm{N}_{2}^{+}+\mathrm{Ar} \longrightarrow \mathrm{Ar}^{+}+\mathrm{N}_{2}+0.185 \mathrm{eV} \\
& \mathrm{N}_{2}^{+}+\mathrm{Ar} \longrightarrow \mathrm{ArN}^{+}+\mathrm{N}-5.70 \mathrm{eV}
\end{aligned}
$$


The inelastic cross section of reaction (11) is measured by Amme and Hayen [28] for energy range $50 \mathrm{eV}$ to $10^{3} \mathrm{eV}$. At low energy, the shape is given by the classical Firsov relation [29] also applicable to symmetric system while the magnitude of this cross section is fitted using the literature data $(\operatorname{Ref}[18])$.

\section{$\underline{\text { 3. Ion transport and reaction coefficients in pure and gas mixtures }}$}

\subsection{Ion swarm coefficients of $\mathrm{Ar}^{+}$and $\mathrm{N}_{2}^{+}$in pure $\mathrm{Ar}, \mathrm{Cl}_{2}$ and $\mathrm{N}_{2}$}

As previously emphasized, the sets of collision cross sections shown in figures 1 up 4 for $\mathrm{Ar}^{+} / \mathrm{Cl}_{2}, \mathrm{Ar}^{+} / \mathrm{N}_{2}, \mathrm{~N}_{2}{ }^{+} / \mathrm{Cl}_{2}$ and $\mathrm{N}_{2}{ }^{+} / \mathrm{Ar}$ systems have been fitted in order to lead to the best agreement possible between calculated and measured ion mobility data and rate coefficients of asymmetric charge transfer. For the considered ion/gas systems, there are experimental ion mobility data only in the case of $\mathrm{N}_{2}^{+} / \mathrm{Ar}$ system. Therefore, in the other systems $\left(\mathrm{Ar}^{+} / \mathrm{Cl}_{2}\right.$, $\mathrm{Ar}^{+} / \mathrm{N}_{2}$ and $\mathrm{N}_{2}^{+} / \mathrm{Cl}_{2}$ ) where there are no experimental data on ion mobility, the momentum transfer cross section fitting fulfils to the following conditions:

- at low $\mathrm{E} / \mathrm{N}$ (in the $\mathrm{E} / \mathrm{N}$ region where mobility shows a plate as a function of $\mathrm{E} / \mathrm{N}$ ), the set of cross sections is chosen to have a good agreement between Monte Carlo simulation and Satoh's relation which already shows confident results in numerous ion/gas systems where there are experimental mobility data at low $\mathrm{E} / \mathrm{N}$,

- at higher $\mathrm{E} / \mathrm{N}$ (after the mobility plate), the potential parameters $\left(\varepsilon_{m}, r_{m}\right.$ and $\left.n\right)$ needed to calculate the elastic momentum transfer cross section (relation 3) are chosen to have a mobility shape similar to the measurements already available in the literature for ion/gas systems having a behaviour close to the studied system in terms of reduced mass and colliding target. For instance, the E/N position of the maximum mobility bump shown in figure 5 in the case of $\mathrm{Ar}^{+} / \mathrm{N}_{2}$ system is chosen close to $180 \mathrm{Td}$ corresponding to the case of a similar ion/gas system taken from literature $\left(\mathrm{K}^{+} / \mathrm{N}_{2}[5]\right)$.

Figure 5 shows the $\mathrm{Ar}^{+}$mobility data over a wide $\mathrm{E} / \mathrm{N}$ range (from $1 \mathrm{Td}$ up to 1000 $\mathrm{Td}$ ) in the case of pure $\mathrm{N}_{2}, \mathrm{Ar}$ and $\mathrm{Cl}_{2}$. The available experimental literature data for $\mathrm{Ar}^{+} / \mathrm{Ar}$ systems and the Satoh's data at low $\mathrm{E} / \mathrm{N}(\mathrm{E} / \mathrm{N}=1 \mathrm{Td})$ are also displayed. First, as previously emphasized, the different sets of collision cross sections are chosen to fit the Satoh's value at low E/N. Then, we also observe the good agreement in the case of $\mathrm{Ar}^{+} / \mathrm{Ar}$ system obtained from the set of the collision cross section taken from the literature (ref [10]). In the case of $\mathrm{Ar}^{+} / \mathrm{N}_{2}$ system, as already emphasized, the potential parameters are chosen in order to have a mobility shape near the E/N bump region $(180 \mathrm{Td})$ similar to mobility data given in the literature in the case of a similar system $\left(\mathrm{K}^{+} / \mathrm{N}_{2}\right.$ [5])). In the case of $\mathrm{Ar}^{+} / \mathrm{Cl}_{2}$ which has an asymmetric charge transfer process exothermic (effective even at low or thermal ion energy), the chosen potential parameters leads to a small bump near about $300 \mathrm{Td}$. The magnitude of the mobility data shown in figure 5 are directly linked to the inverse of the magnitude to the total collision cross sections (or $Q_{\text {tot }}$ collision frequency). Indeed, the relation between mobility $K_{0}(E / N)$, isotropic part of ion distribution $\phi_{0}\left(\varepsilon_{r}\right)$ and total collision frequency $v_{t o t}\left(v_{t o t}\left(\varepsilon_{r}\right)=N\left(2 \varepsilon_{r} / M_{r}\right)^{1 / 2} Q_{t o t}\left(\varepsilon_{r}\right)\right)$ can be written as:

$$
K_{0}(E / N) \propto \int_{0}^{\infty} \frac{\varepsilon_{r}^{3 / 2}}{v_{t o t}\left(\varepsilon_{r}\right)} \frac{\partial \phi_{0}\left(\varepsilon_{r}, E / N\right)}{\partial \varepsilon_{r}} d \varepsilon_{r}
$$

This is why the mobility of $\mathrm{Ar}^{+}$in $\mathrm{N}_{2}$ corresponding to the lowest total collision cross section (or collision frequency) is the highest one and the $\mathrm{Ar}^{+} / \mathrm{Cl}_{2}$ mobility is the lowest one. 
Figure 6 shows the $\mathrm{N}_{2}{ }^{+}$mobility data over a wide $\mathrm{E} / \mathrm{N}$ range in the case of the same pure gases $\left(\mathrm{N}_{2}, \mathrm{Ar}\right.$ and $\left.\mathrm{Cl}_{2}\right)$. The available experimental literature data for $\mathrm{N}_{2}{ }^{+} / \mathrm{Ar}$ and $\mathrm{N}_{2}{ }^{+} / \mathrm{N}_{2}$ systems and the Satoh's data at low $\mathrm{E} / \mathrm{N}(\mathrm{E} / \mathrm{N}=1 \mathrm{Td})$ are also displayed. First, figure 6 confirms that the different sets of collision cross sections fit the Satoh's value at low E/N. Then, there are a good agreements between the calculated and measured mobility data in the case of the fitted $\mathrm{N}_{2}^{+} / \mathrm{Ar}$ set and the $\mathrm{N}_{2}^{+} / \mathrm{N}_{2}$ set taken from the literature (ref [11]). In the case of $\mathrm{N}_{2}{ }^{+} / \mathrm{Cl}_{2}$ which has also an asymmetric charge transfer process exothermic (effective like $\mathrm{Ar}^{+} / \mathrm{Cl}_{2}$ even at low or thermal ion energy), the chosen potential parameters leads to a small bump near about $400 \mathrm{Td}$ due to an energy $\varepsilon_{m}$ of the well depth potential higher than the one corresponding to $\mathrm{Ar}^{+} / \mathrm{Cl}_{2}$ system. Furthermore as already emphasized, the magnitude of mobility data is inversely proportional to the total collision frequency. Therefore the mobility of $\mathrm{N}_{2}{ }^{+}$in Ar corresponding to the lowest total collision frequency is the highest one and the $\mathrm{N}_{2}{ }^{+} / \mathrm{Cl}_{2}$ mobility is the lowest one.

Figure 7 displays as a function of mean ion energy a comparison between measured (Ref [19]) and calculated reaction rate coefficients of asymmetric charge transfer for $\mathrm{Ar}+/ \mathrm{N}_{2}$ system for three gas temperatures. The good agreement between measurement and calculation confirms the good choice of the inelastic collision cross section shown in figure 2 for the asymmetric charge transfer process.

Figure 8 shows the variation over a wide $\mathrm{E} / \mathrm{N}$ range $(1 \mathrm{Td}$ up to $1000 \mathrm{Td})$ of the inelastic reaction coefficients for asymmetric charge transfer for $\mathrm{Ar}^{+} / \mathrm{N}_{2}, \mathrm{Ar}^{+} / \mathrm{Cl}_{2}, \mathrm{~N}_{2}{ }^{+} / \mathrm{Ar}$ and $\mathrm{N}_{2}{ }^{+} / \mathrm{Cl}_{2}$. The available experimental data at thermal or gas energy are also displayed at low $\mathrm{E} / \mathrm{N}$ (1 Td). Obviously these inelastic reaction rate coefficients are very useful for the modelling of the ion chemistry inside the plasma discharge reactor particularly in the case of the crystal photonics applications.

The behaviour as a function of $\mathrm{E} / \mathrm{N}$ of other ion data as for instance the longitudinal diffusion coefficients $\mathrm{ND}_{\mathrm{L}}$ (very useful for a better understanding of the ion transport in plasma discharge of our interest) are shown in figures 9 and 10. The shape and the magnitude of the diffusion coefficient of each ion/gas systems are obviously completely determined by the total collision frequency $v_{\text {tot }}\left(\varepsilon_{\mathrm{r}}\right)$ behaviour. In fact the isotropic diffusion coefficient $\mathrm{D}$ which is an average between transversal $D_{T}$ and longitudinal $D_{L}$ diffusion coefficients $(D=$ $\left.\left(\mathrm{D}_{\mathrm{L}}+2 \mathrm{D}_{\mathrm{T}}\right) / 3\right)$ is inversely proportional to $v_{\text {tot }}\left(\varepsilon_{\mathrm{r}}\right)$ :

$$
N D(E / N) \propto \int_{0}^{\infty} \frac{\varepsilon_{r}^{3 / 2}}{v_{t o t}\left(\varepsilon_{r}\right)} \phi_{0}\left(\varepsilon_{r}, E / N\right) d \varepsilon_{r}
$$

For instance in figure 9 showing $\mathrm{Ar}^{+}$in the different gases $\left(\mathrm{Ar}, \mathrm{N}_{2}\right.$ and $\mathrm{Cl}_{2}$ ), at relatively low $\mathrm{E} / \mathrm{N}$ the lowest diffusion coefficient corresponds to $\mathrm{Ar}^{+} / \mathrm{Cl}_{2}$ system due to the highest total collision frequency. The crossing of $\mathrm{ND}_{\mathrm{L}}$ of $\mathrm{Ar}^{+} / \mathrm{Cl}_{2}$ with the one of $\mathrm{Ar}^{+} / \mathrm{Ar}$ at $\mathrm{E} / \mathrm{N}$ around 150 $\mathrm{Td}$ is due to the inelastic charge transfer that becomes larger for $\mathrm{Ar}^{+} / \mathrm{Ar}$. This obviously leads to a lower ion mean energy in presence of such inelastic processes with the same consequence on the longitudinal characteristic energy or diffusion coefficient. A quite similar behaviour of $\mathrm{ND}_{\mathrm{L}}$ in the case of $\mathrm{N}_{2}{ }^{+}$ion in $\mathrm{Ar}, \mathrm{N}_{2}$ and $\mathrm{Cl}_{2}$ can be also observed in figure 10.

\subsection{Ion swarm coefficients of $\mathrm{Ar}^{+}$and $\mathrm{N}_{2}^{+}$in binary and ternary mixtures involving $\mathrm{Ar}, \mathrm{Cl}_{2}$ and $\mathrm{N}_{2}$}

From the knowledge of the sets of elastic and inelastic collision cross sections in the different pure gases $\left(\mathrm{Ar}^{+} / \mathrm{Cl}_{2}, \mathrm{Ar}^{+} / \mathrm{N}_{2}, \mathrm{~N}_{2}{ }^{+} / \mathrm{Cl}_{2}\right.$ and $\mathrm{N}_{2}{ }^{+} / \mathrm{Ar}$ ), it is therefore possible to calculate from Monte Carlo simulations the transport and reaction coefficients of $\mathrm{Ar}^{+}$and also $\mathrm{N}_{2}{ }^{+}$in the case of the different binary $\left(\mathrm{Ar}-\mathrm{Cl}_{2}\right.$ or $\left.\mathrm{N}_{2}-\mathrm{Cl}_{2}\right)$ and ternary $\left(\mathrm{Ar}_{-}-\mathrm{Cl}_{2}-\mathrm{N}_{2}\right)$ mixtures. It is worth noting that the ion data in the gas mixtures are generally obtained from linearity laws as 
for instance Blanc's law giving the ion mobility $K_{\text {mix }}$ for a gas mixture from the knowledge of mobility data $K_{n}$ of pure gases ( $x_{n}$ being the mole fraction of the gas of the species $n$ and $K_{n}$ the corresponding ion mobility).

$$
\frac{1}{K_{m i x}}=\sum_{n} \frac{x_{n}}{K_{n}}
$$

However, the validity of Blanc's law is normally limited to the cases where there are only elastic processes and when the ion energy distribution function is maxwellian. In the following the ion mobility data obtained from Monte Carlo simulations are given in different binary and ternary mixtures and compared to Blanc's law.

Figures $11 \mathrm{a}$ and $11 \mathrm{~b}$ show the inverse of $\mathrm{Ar}^{+}$mobility in the binary $\mathrm{Ar}-\mathrm{Cl}_{2}$ mixtures as a function of the proportion of $\mathrm{Cl}_{2}$ at $100 \mathrm{Td}$ (Fig 11a) and $1000 \mathrm{Td}$ (Fig. 11b). At $100 \mathrm{Td}$, the increase of $1 / K_{\text {mix }}$ as a function $\mathrm{Cl}_{2}$ proportion in the $\mathrm{Ar}^{-\mathrm{Cl}_{2}}$ mixture obviously corresponds to a case where the total collision frequency is lower for the low $\mathrm{Cl}_{2}$ proportion and then becomes higher with the $\mathrm{Cl}_{2}$ proportion rise because the inverse of mobility is directly proportional to the total collision frequency (see relation 13). This trend is reversed at 1000 $\mathrm{Td}$ due to the presence of inelastic processes which play a larger role. Furthermore, there is a small but visible deviation between Monte Carlo calculation and Blanc's law at $100 \mathrm{Td}$ (about $3 \%$ ). This deviation is paradoxically lower or negligible at $1000 \mathrm{Td}$ because the inelastic processes are supposed to play a larger role when $\mathrm{E} / \mathrm{N}$ increases. In fact the negligible deviation from Blanc's law at $1000 \mathrm{Td}$ is due to the specific shape and magnitude of inelastic processes at intermediate energy range (corresponding to the ion energy distribution for 1000 Td) in both $\mathrm{Ar}^{+} / \mathrm{Ar}$ (large symmetric charge transfer) and $\mathrm{Ar}^{+} / \mathrm{Cl}_{2}$ (lower asymmetric charge transfer in the same energy range).

Figures $12 \mathrm{a}$ and $12 \mathrm{~b}$ show the inverse of $\mathrm{N}_{2}{ }^{+}$mobility in the binary $\mathrm{Ar}-\mathrm{Cl}_{2}$ mixtures as a function of the proportion of $\mathrm{Cl}_{2}$ at $100 \mathrm{Td}$ (Fig 12a) and $1000 \mathrm{Td}$ (Fig. 12b). In this case the trend of the variation of the inverse of the mobility is the same as in figures $11: 1 / K_{\text {mix }}$ increases with $\mathrm{Cl}_{2}$ proportion at $100 \mathrm{Td}$ and decreases at $1000 \mathrm{Td}$. However, whatever E/N $(100 \mathrm{Td}$ or $1000 \mathrm{td})$ there is a deviation that reaches about $5 \%$ between Monte Carlo simulation and Blanc's law.

Figures $13 \mathrm{a}$ and $13 \mathrm{~b}$ show the inverse of $\mathrm{Ar}^{+}$mobility in the ternary $\mathrm{Ar}-\mathrm{N}_{2}-\mathrm{Cl}_{2}$ mixtures as a function of the proportion of $\mathrm{Cl}_{2}$ at $100 \mathrm{Td}$ (Fig 13a) and $1000 \mathrm{Td}$ (Fig. 13b). It is worth noting that $\mathrm{Ar}$ and $\mathrm{N}_{2}$ have the same proportion whatever the $\mathrm{Cl}_{2}$ proportion. In this case the trend of the variation of the inverse of the mobility is not the same as in the previous case at $1000 \mathrm{Td}$. Indeed, $1 / K_{\text {mix }}$ increases with $\mathrm{Cl}_{2}$ proportion for both $\mathrm{E} / \mathrm{N}$ values $(100 \mathrm{Td}$ and 1000 Td). This increase of $1 / K_{\text {mix }}$ at $\mathrm{E} / \mathrm{N}=1000 \mathrm{Td}$ from about $1.1 \mathrm{~V} \mathrm{~s} \mathrm{~cm}^{-2}\left(1 / K_{\text {mix }}\right.$ value for $\mathrm{Ar}^{+}$in $50 \% \mathrm{~N}_{2}-50 \% \mathrm{Ar}$ ) up to $1.4 \mathrm{~V} \mathrm{~s} \mathrm{~cm}^{-2}$ (value for $\mathrm{Ar}^{+}$in $100 \% \mathrm{Cl}_{2}$ ) is coherent with the results already shown in figure $11 \mathrm{~b}$ in the case of $\mathrm{Ar}^{+}$in the binaryAr-Cl $\mathrm{Cl}_{2}$ mixture. This is due to the specific shape and magnitude in the intermediate energy range of the elastic and inelastic collision cross sections of $\mathrm{Ar}^{+}$interacting with the different neutral species $\left(\mathrm{Ar}, \mathrm{N}_{2}\right.$ and $\left.\mathrm{Cl}_{2}\right)$.

Figures $14 \mathrm{a}$ and $14 \mathrm{~b}$ show the inverse of $\mathrm{N}_{2}{ }^{+}$mobility in the ternary $\mathrm{Ar}-\mathrm{N}_{2}-\mathrm{Cl}_{2}$ mixtures as a function of the proportion of $\mathrm{Cl}_{2}$ at $100 \mathrm{Td}$ (Fig 13a) and $1000 \mathrm{Td}$ (Fig. 13b). The proportions of $\mathrm{Ar}$ and $\mathrm{N}_{2}$ are the same in the mixture when the $\mathrm{Cl}_{2}$ proportion varies. In this case, the trend of the variation of $1 / K_{\text {mix }}$ is also similar to the trend already observed in figures 11 and 12 : $1 / K_{\text {mix }}$ increases with $\mathrm{Cl}_{2}$ proportion at $100 \mathrm{Td}$ and decreases at $1000 \mathrm{Td}$. Furthermore, whatever the $\mathrm{E} / \mathrm{N}$ value $(100 \mathrm{Td}$ or $1000 \mathrm{td})$ the deviation between Monte Carlo simulation and Blanc's law is always present and reach a maximum of $10 \%$. 


\section{Conclusion}

The ion swarm transport coefficients (reduced mobility, diffusion coefficients and reaction rate coefficients) of $\mathrm{Ar}^{+} / \mathrm{Cl}_{2}, \mathrm{Ar}^{+} / \mathrm{N}_{2}, \mathrm{~N}_{2}{ }^{+} / \mathrm{Cl}_{2}$ and $\mathrm{N}_{2}{ }^{+} / \mathrm{Ar}$ have been determined from a Monte Carlo simulation using calculated elastic and experimentally estimated inelastic collision cross sections. The calculation of elastic momentum transfer cross sections are based on a semi-classical JWKB approximation using on a rigid core interaction potential model while the inelastic cross sections have been fitted using the measured ion conversion reaction coefficients. Then, the cross sections sets are fitted using at low $\mathrm{E} / \mathrm{N}$ range the zerofield mobility calculated from the Satoh's relation and the measured mobility data available in the literature for $\mathrm{N}_{2}^{+} / \mathrm{Ar}$. For the other systems where there are no experimental mobility data at higher $\mathrm{E} / \mathrm{N}$ range, we used the physical properties of each considered ion/gas system. The sets of elastic and inelastic collision cross sections are then given for the first time in the literature in $\mathrm{Ar}^{+} / \mathrm{Cl}_{2}, \mathrm{Ar}^{+} / \mathrm{N}_{2}, \mathrm{~N}_{2}^{+} / \mathrm{Cl}_{2}$ and $\mathrm{N}_{2}^{+} / \mathrm{Ar}$ systems. Then, the ion transport and reaction coefficients are calculated also for the first time in the literature over a wide range of $\mathrm{E} / \mathrm{N}$ for $\mathrm{Ar}^{+}$and $\mathrm{N}_{2}{ }^{+}$in pure gases and also in binary and ternary mixtures involving $\mathrm{Cl}_{2}, \mathrm{Ar}$ and $\mathrm{N}_{2}$. The deviations between the mobility data calculated from Monte Carlo simulations and the linear Blanc's law are also analysed in the case of different gas mixtures ; these deviations do not exceed $10 \%$ in the chosen $\mathrm{E} / \mathrm{N}$ range. The ion swarm data given in this work are needed for the modelling and simulation of non equilibrium low pressure electrical discharges used more particularly for etching of the III-V compounds in the field of crystal photonic applications.

\section{Acknowledgement:}

This work has been undertaken in the framework of an international cooperation between CNRS (French Center of Scientific Research) and MESRS (Algerian Ministry of higher Education and Research).

\section{References:}

[1] Rhallabi A 2005 Journal of Vacuum Science Technology B: Microelectronics and Nanometer Structures 231984

[2] Edwards G T, Sobiesierski A, Westwood D I, and Smowton P M 2007 Semiconductor Science Technology 221010

[3] Hahn Y B, Hays D C, Donovan S M, Abernathy C R, Han J, Shul R J, Cho H, Jung K B, and Pearton S J 1999 Journal of Vacuum Science Technology A 17768

[4] Lai Y H, Yeh C T, Hwang J M, Hwang H L, Chen C T, and Hung W H 2001 Journal of Physical Chemistry B 10510029

[5] Ellis H W, Pai R Y, McDaniel E W, Mason E A and Viehland L A 1976 Atomic Data and Nuclear Data Tables 17 177-210 ; Ellis H W, McDaniel E W, Albritton D L, Viehland L A, Lin S L and Mason E A 1978 Atomic Data and Nuclear Data Tables 22 179-217; Ellis H W, Thackston M G, McDaniel E W and Mason E A 1984 Atomic Data and Nuclear Data Tables 31 113-51

[6] Viehland L A and E.A. Mason 1995 Atom. Data Nucl. Tab. 6037

[7] Petrovic Z, Raspopovic Z M, Stojanovic V D, Jovanovic J V, Malovic G, Makabe T, De Urquijo J 2007 Appl. Surf. Sc. 2536619 
[8] Nelson D, Benhenni M, Eichwald O, and Yousfi M 2003 J. Appl. Phys. 9496

[9] Yousfi M, Hennad A and Benhenni M 2007 J. Phys. D: Appl. Phys. 401751

[10] Phelps A V 1992 J. Phys. Chem. Ref. Data 21, 883

[11] Phelps A V 1991 J. Phys. Chem. Ref. Data, 20 557; Hennad A 1996 PhD Thesis

University Paul Sabatier of Toulouse, France

[12] Subbramonuim P and Kushner M J 2002 J. Vac. Sci. Technol. A 14325

[13] Yousfi M, Hennad A, and Eichwald O 1998 J. Appl. Phys. 844161

[14] Satoh Y, Takebe M, and Iinuma K, 1987 J. Chem. Phys. 876250

[15] Munn R J, Mason E A, and Smith F J, 1964 J. Chem. Phys. 41 3978; Mason E A and Schamp H W, 1958 Annual Physics 4233

[16] Murrell J N 1982 Chem. Phys. Lett. 93521

[17] Spanel P, Tichy M, and Smith D 1993 Int. J. Mass Spectrom. Ion Processes 129155

[18] Ikezoe Y, Matsuoka S, Takebe M, and Viggiano A 1986 Gas phase Ion-Molecule reaction rate constants through 1986, Ion reaction research group of mass spectroscopy society of Japan

[19] Viggiano A, Van Doren J M, Morris R A, and Paulson J F 1990 J. Chem. Phys. 934761

[20] Smith D and Adams N G 1981 Phys. Rev. A 232327

[21] Liao C L, Shao J D, Xu R, Flesch G D, Li Y G, and Ng C Y 1986 J. Chem. Phys. 85 3874

[22] Liao C L, Xu R, and Ng C Y 1986 J. Chem. Phys. 841948

[23] Flesch G D and Ng C Y 1990 J. Chem. Phys. 922876

[24] Flesch G D and Ng C Y 1992 J. Chem. Phys. 97162

[25] Tosi P, Dmitrijev O, and Bassi D 1992 Chem. Phys. Letters 200483

[26] Anicich V G 1993 J. Phys. Chem. Ref. Data 221469

[27] Tosi P, Correale R, Lu W, and Bassi D 1999 J. Chem. Phys. 1104276

[28] Amme R C and Hayden H C 1965 J. Chem. Phys. 422011

[29] Firsov O B 1951 Sov. Phys. JETP 211001

[30] Basurto E, De Urquijo J, Alvarez I, and Cisneros C 2000 Phys. Rev. E 613053 


\section{Figure Captions:}

Figure 1 : Set of collision cross sections for elastic momentum transfer $Q m$ and non-resonant charge transfer $Q\left(\mathrm{Cl}_{2}{ }^{+}, \mathrm{Cl}^{+}\right)$processes in the case of $\mathrm{Ar}^{+} / \mathrm{Cl}_{2}$ system

Figure 2: Set of collision cross sections for elastic momentum transfer $Q m$ and non-resonant charge transfer $Q\left(N_{2}^{+}\right)$processes in the case of $\mathrm{Ar}^{+} / \mathrm{N}_{2}$ system

Figure 3: Set of collision cross sections for elastic momentum transfer $Q m$ and non-resonant charge transfer $Q\left(\mathrm{Cl}_{2}{ }^{+}\right)$processes in the case of $\mathrm{N}_{2}{ }^{+} / \mathrm{Cl}_{2}$ system

Figure 4: Set of collision cross sections for elastic momentum transfer $Q m$ and non-resonant charge transfer $Q\left(\mathrm{Ar}^{+}\right)$processes in the case of $\mathrm{N}_{2}^{+} /$Ar system

Figure 5: Reduced ion mobility as a function of $\mathrm{E} / \mathrm{N}$ for $\mathrm{Ar}^{+}$in pure $\mathrm{Ar}, \mathrm{Cl}_{2}$ and $\mathrm{N}_{2}$ with comparison with Satoh's relation $(\boldsymbol{\Lambda})$ at low E/N and comparison with experimental mobility data (Basurto et al [30]) in the case of $\mathrm{Ar}^{+} / \mathrm{Ar}$

Figure 6: Reduced ion mobility as a function of $\mathrm{E} / \mathrm{N}$ for $\mathrm{N}_{2}{ }^{+}$in pure $\mathrm{Ar}, \mathrm{Cl}_{2}$ and $\mathrm{N}_{2}$ with comparisons with Satoh's relation $(\boldsymbol{\Delta})$ at low E/N and comparison with the experimental mobility data (Ellis et at compilation [5]) in the cases of $\mathrm{N}_{2}^{+} / \mathrm{Ar}$ and $\mathrm{N}_{2}{ }^{+} / \mathrm{N}_{2}$

Figure 7: Comparison between measured and calculated reaction rate coefficients of nonresonant charge transfer process for interactions of $\mathrm{Ar}^{+}$with $\mathrm{N}_{2}$ (reaction 5). Experimental data (Viaggiano et al [19]) are given for different gas temperatures.

Figure 8: Inelastic collision rate coefficients as a function of $\mathrm{E} / \mathrm{N}$ in the cases of $\mathrm{Ar}^{+} / \mathrm{Cl}_{2}$, $\mathrm{Ar}^{+} / \mathrm{N}_{2}, \mathrm{~N}_{2}{ }^{+} / \mathrm{Cl}_{2}$ and $\mathrm{N}_{2}+/$ Ar systems Symbols are taken from the experimental data of Ikezeo et al [18] and the compilation of Anicich [26]

Figure 9: Longitudinal ion diffusion coefficient as a function of $\mathrm{E} / \mathrm{N}$ in the case of $\mathrm{Ar}^{+}$ interacting with pure $\mathrm{Ar}, \mathrm{Cl}_{2}$ and $\mathrm{N}_{2}$

Figure 10: Longitudinal ion diffusion coefficient as a function of $\mathrm{E} / \mathrm{N}$ in the case of $\mathrm{N}_{2}{ }^{+}$ interacting with pure $\mathrm{Ar}, \mathrm{Cl}_{2}$ and $\mathrm{N}_{2}$

Figure 11a: The inverse of $\mathrm{Ar}^{+}$mobility in the $\mathrm{Ar}^{-} \mathrm{Cl}_{2}$ mixtures as a function of the proportion of $\mathrm{Cl}_{2}$ at $100 \mathrm{Td}$. Monte Carlo calculations (Solid line) are compared to Blanc's law (Dashed line)

Figure 11b: The inverse of $\mathrm{Ar}^{+}$mobility in the $\mathrm{Ar}-\mathrm{Cl}_{2}$ mixtures as a function of the proportion of $\mathrm{Cl}_{2}$ at $1000 \mathrm{Td}$. Monte Carlo calculations (Solid line) are compared to Blanc's law (symbols)

Figure 12a: The inverse of $\mathrm{N}_{2}{ }^{+}$mobility in the $\mathrm{N}_{2}-\mathrm{Cl}_{2}$ mixtures as a function of the proportion of $\mathrm{Cl}_{2}$ at $100 \mathrm{Td}$. Monte Carlo calculations (Solid line) are compared to Blanc's law (Dashed line)

Figure 12b: The inverse of $\mathrm{N}_{2}^{+}$mobility in the $\mathrm{N}_{2}-\mathrm{Cl}_{2}$ mixtures as a function of the proportion of $\mathrm{Cl}_{2}$ at $1000 \mathrm{Td}$. Monte Carlo calculations (Solid line) are compared to Blanc's law (Dashed line)

Figure 13a: The inverse of $\mathrm{Ar}^{+}$mobility in the $\mathrm{Ar}-\mathrm{N}_{2}-\mathrm{Cl}_{2}$ mixtures as a function of the proportion of $\mathrm{Cl}_{2}$ at $100 \mathrm{Td}$. Noting that $\mathrm{Ar}$ and $\mathrm{N}_{2}$ have the same proportion whatever the $\mathrm{Cl}_{2}$ proportion. Monte Carlo calculations (Solid line) are compared to Blanc's law (Dashed line).

Figure 13b: The inverse of $\mathrm{Ar}^{+}$mobility in the $\mathrm{Ar}-\mathrm{N}_{2}-\mathrm{Cl}_{2}$ mixtures as a function of the proportion of $\mathrm{Cl}_{2}$ at $1000 \mathrm{Td}$. Noting that $\mathrm{Ar}$ and $\mathrm{N}_{2}$ have the same proportion whatever the $\mathrm{Cl}_{2}$ proportion. Monte Carlo calculations (Solid line) are compared to Blanc's law (Symbols) 
Figure 14a: The inverse of $\mathrm{N}_{2}{ }^{+}$mobility in the $\mathrm{Ar}-\mathrm{N}_{2}-\mathrm{Cl}_{2}$ mixtures as a function of the proportion of $\mathrm{Cl}_{2}$ at $100 \mathrm{Td}$. Noting that $\mathrm{Ar}$ and $\mathrm{N}_{2}$ have the same proportion whatever the $\mathrm{Cl}_{2}$ proportion. Monte Carlo calculations (Solid line) are compared to Blanc's law (Dashed line).

Figure 14b: The inverse of $\mathrm{N}_{2}^{+}$mobility in the $\mathrm{Ar}-\mathrm{N}_{2}-\mathrm{Cl}_{2}$ mixtures as a function of the proportion of $\mathrm{Cl}_{2}$ at $100 \mathrm{Td}$. Noting that $\mathrm{Ar}$ and $\mathrm{N}_{2}$ have the same proportion whatever the $\mathrm{Cl}_{2}$ proportion. Monte Carlo calculations (Solid line) are compared to Blanc's law (Dashed line). 


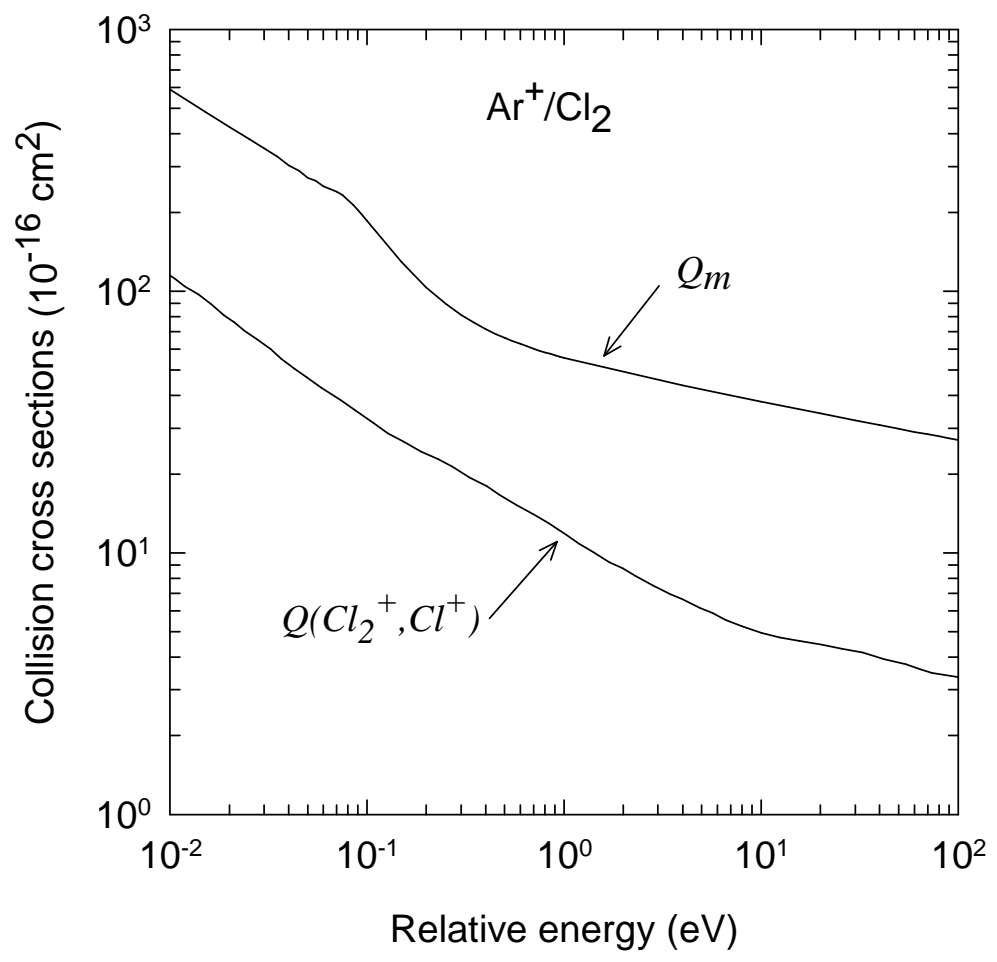

Figure 1 : Set of collision cross sections for elastic momentum transfer $Q m$ and non-resonant charge transfer $Q\left(\mathrm{Cl}_{2}{ }^{+}, \mathrm{Cl}^{+}\right)$processes in the case of $\mathrm{Ar}^{+} / \mathrm{Cl}_{2}$ system

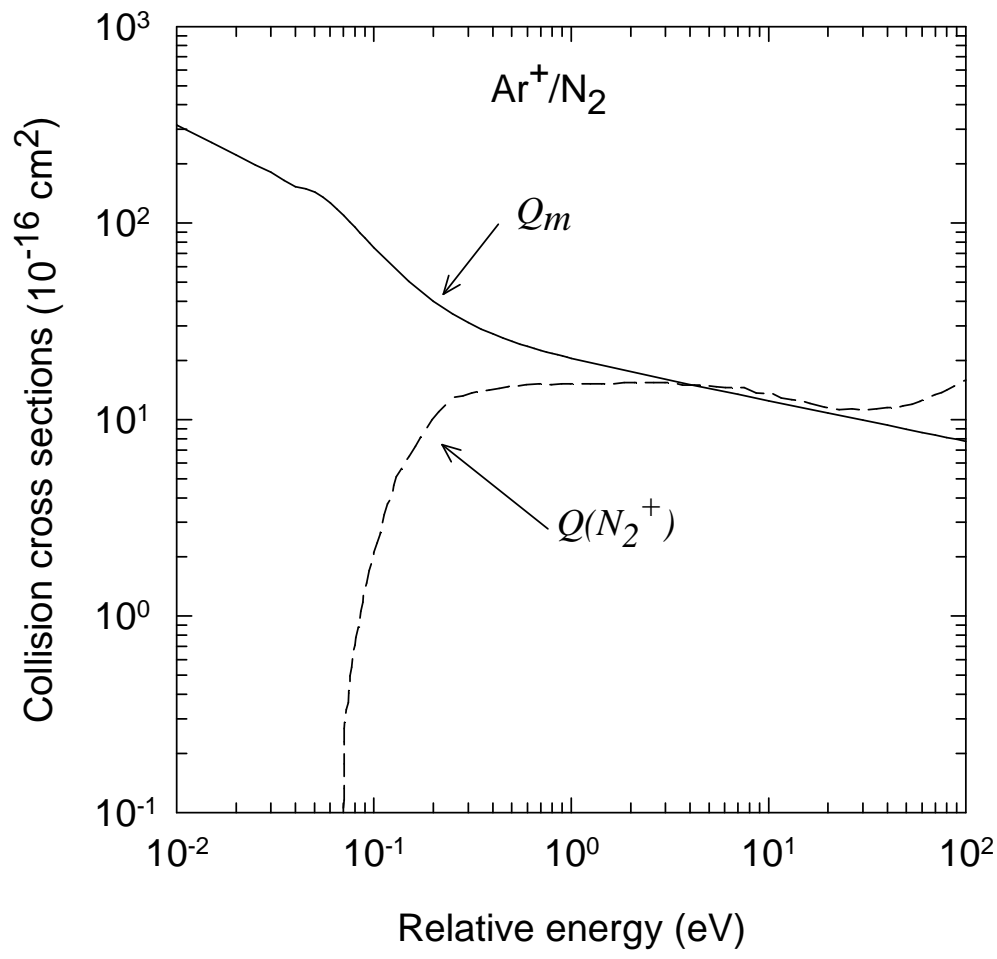

Figure 2: Set of collision cross sections for elastic momentum transfer $Q m$ and non-resonant charge transfer $Q\left(N_{2}^{+}\right)$processes in the case of $\mathrm{Ar}^{+} / \mathrm{N}_{2}$ system 


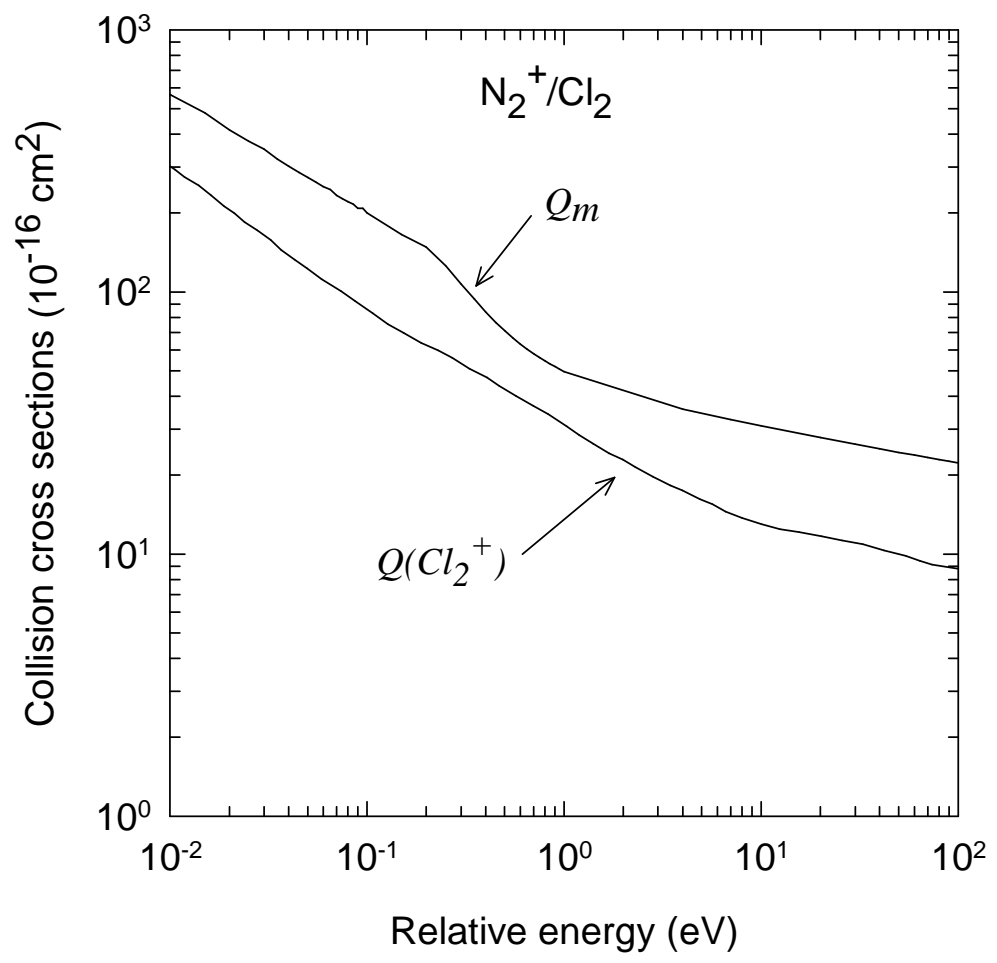

Figure 3: Set of collision cross sections for elastic momentum transfer $Q m$ and non-resonant charge transfer $Q\left(\mathrm{Cl}_{2}{ }^{+}\right)$processes in the case of $\mathrm{N}_{2}{ }^{+} / \mathrm{Cl}_{2}$ system

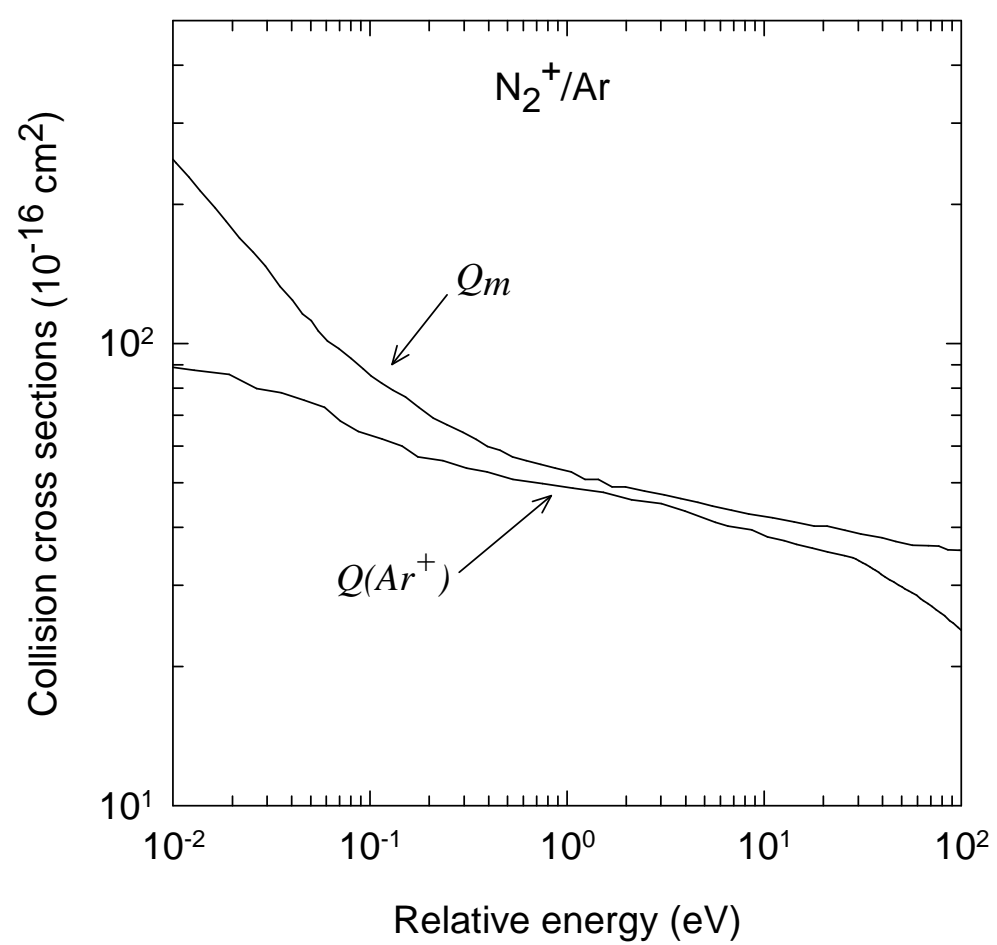

Figure 4: Set of collision cross sections for elastic momentum transfer $Q m$ and non-resonant charge transfer $Q\left(\mathrm{Ar}^{+}\right)$processes in the case of $\mathrm{N}_{2}^{+} /$Ar system 


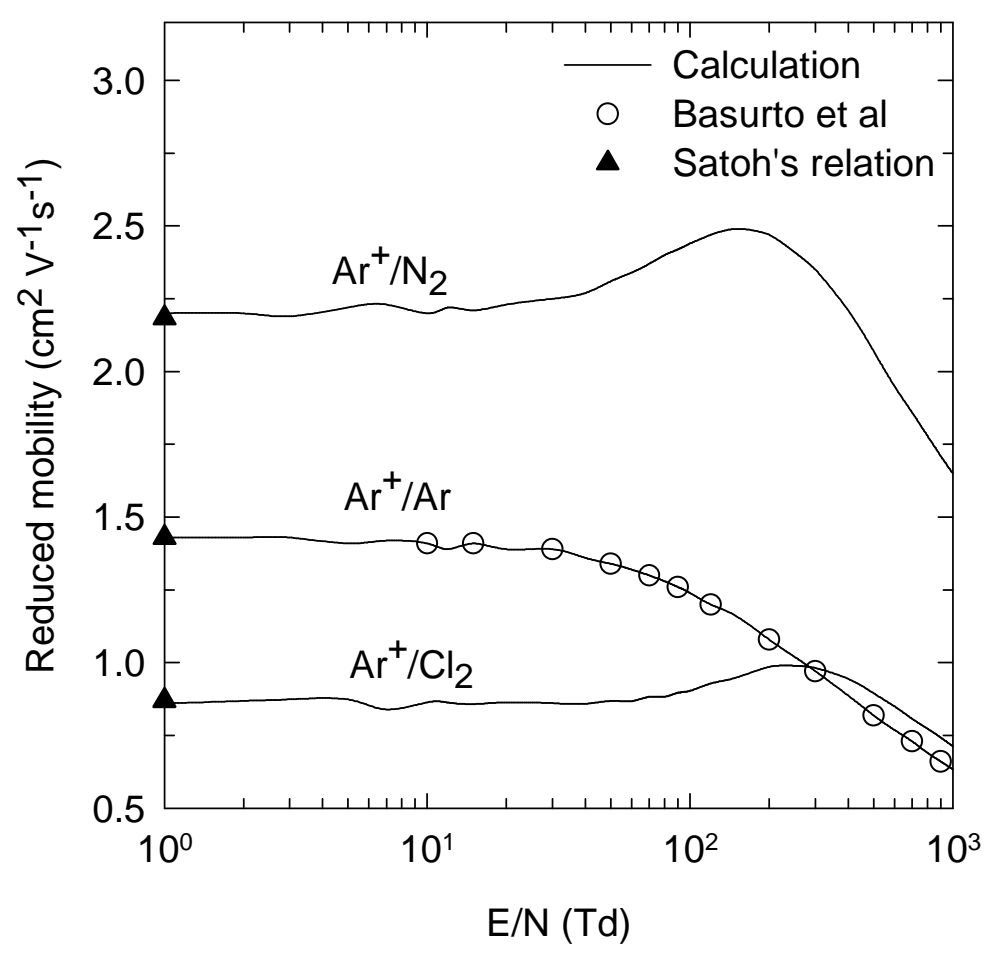

Figure 5: Reduced ion mobility as a function of $\mathrm{E} / \mathrm{N}$ for $\mathrm{Ar}^{+}$in pure $\mathrm{Ar}, \mathrm{Cl}_{2}$ and $\mathrm{N}_{2}$ with comparison with Satoh's relation $(\mathbf{\Lambda})$ at low E/N and comparison with experimental mobility data (Basurto et al [30]) in the case of $\mathrm{Ar}^{+} / \mathrm{Ar}$

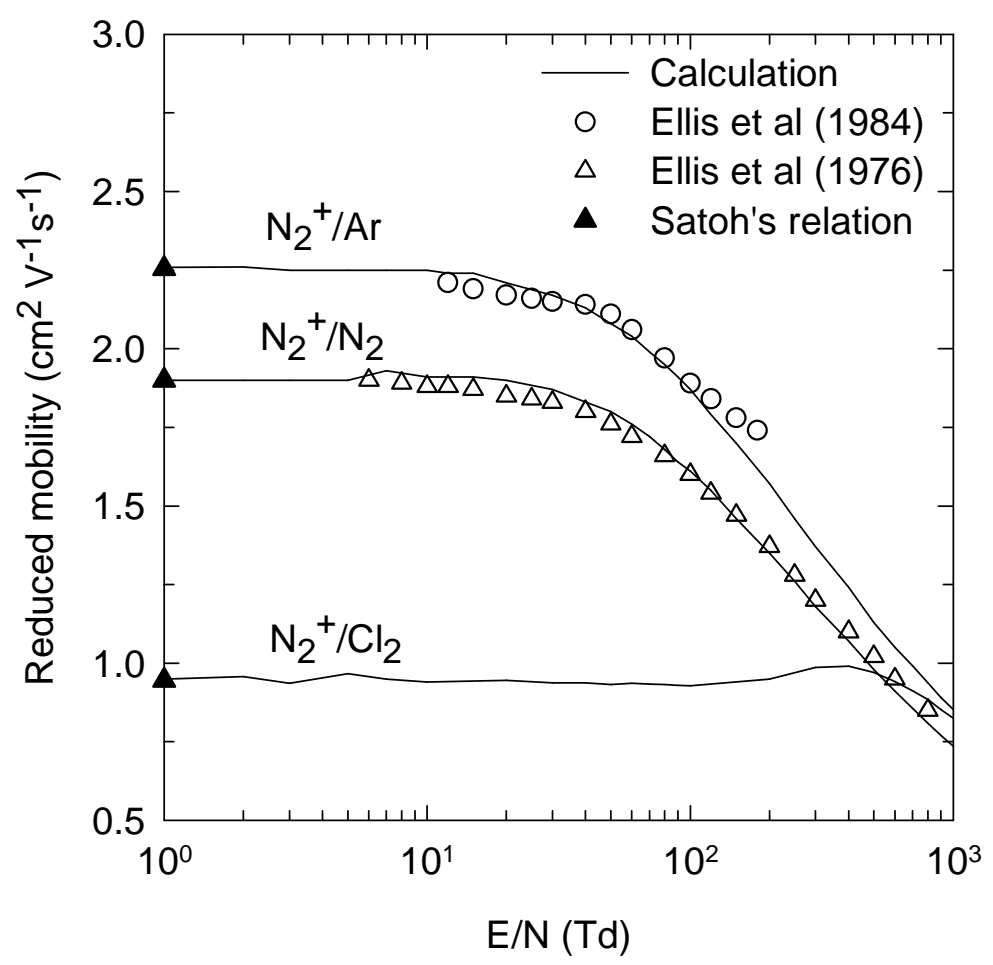

Figure 6: Reduced ion mobility as a function of $\mathrm{E} / \mathrm{N}$ for $\mathrm{N}_{2}{ }^{+}$in pure $\mathrm{Ar}, \mathrm{Cl}_{2}$ and $\mathrm{N}_{2}$ with comparisons with Satoh's relation ( $\mathbf{\Lambda})$ at low E/N and comparison with the experimental mobility data (Ellis et at compilation [5]) in the cases of $\mathrm{N}_{2}{ }^{+} / \mathrm{Ar}$ and $\mathrm{N}_{2}{ }^{+} / \mathrm{N}_{2}$ 


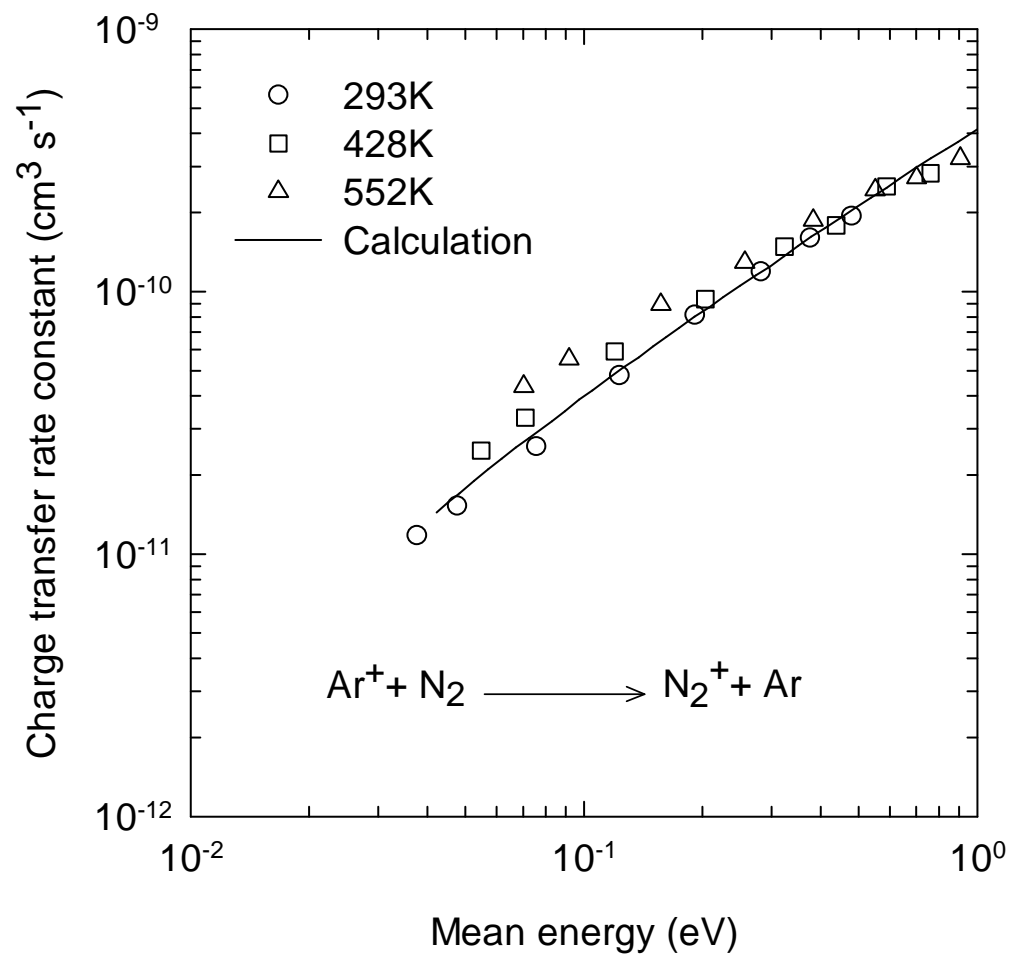

Figure 7: Comparison between measured and calculated reaction rate coefficients of nonresonant charge transfer process for interactions of $\mathrm{Ar}^{+}$with $\mathrm{N}_{2}$ (reaction 5). Experimental data (Viaggiano et [19]) are given for different gas temperatures.

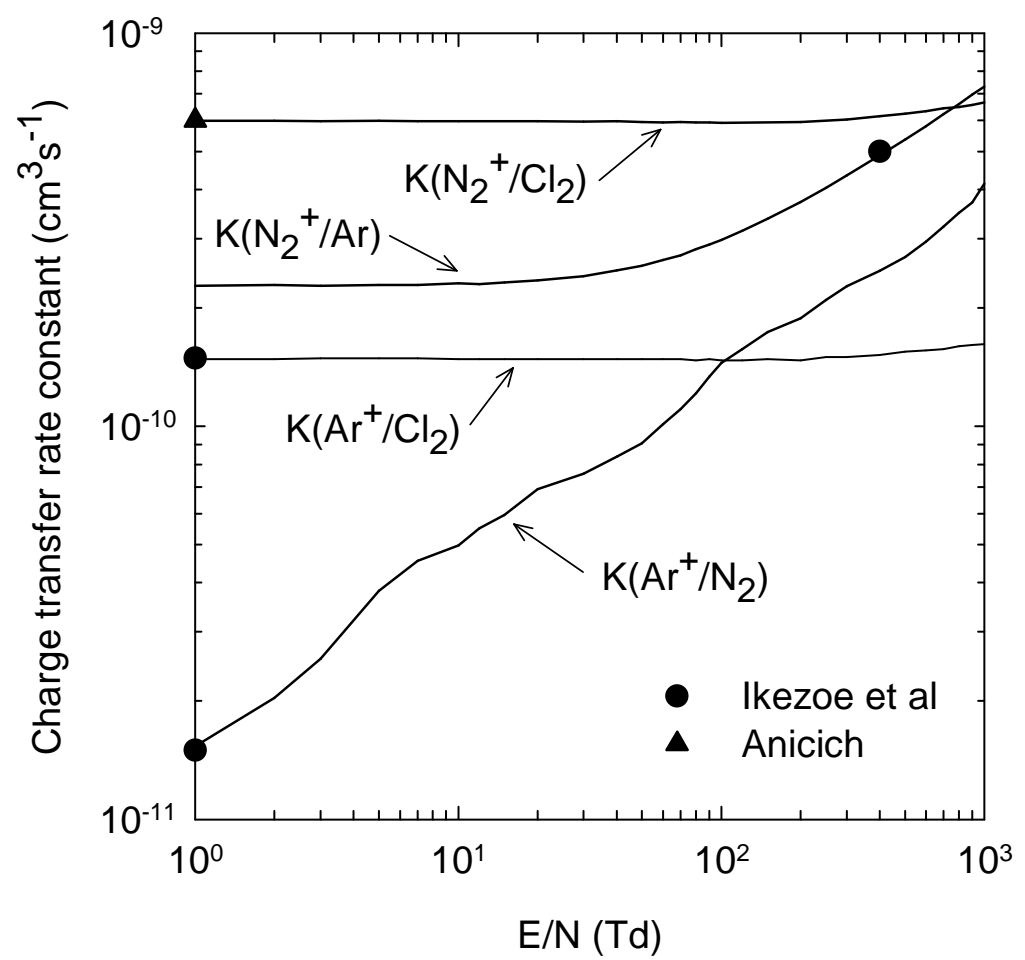

Figure 8: Inelastic collision rate coefficients as a function of $\mathrm{E} / \mathrm{N}$ in the cases of $\mathrm{Ar}^{+} / \mathrm{Cl}_{2}$, $\mathrm{Ar}^{+} / \mathrm{N}_{2}, \mathrm{~N}_{2}{ }^{+} / \mathrm{Cl}_{2}$ and $\mathrm{N}_{2}+/ \mathrm{Ar}$ systems Symbols are taken from the experimental data of Ikezeo et al [18] and the compilation of Anicich [26] 


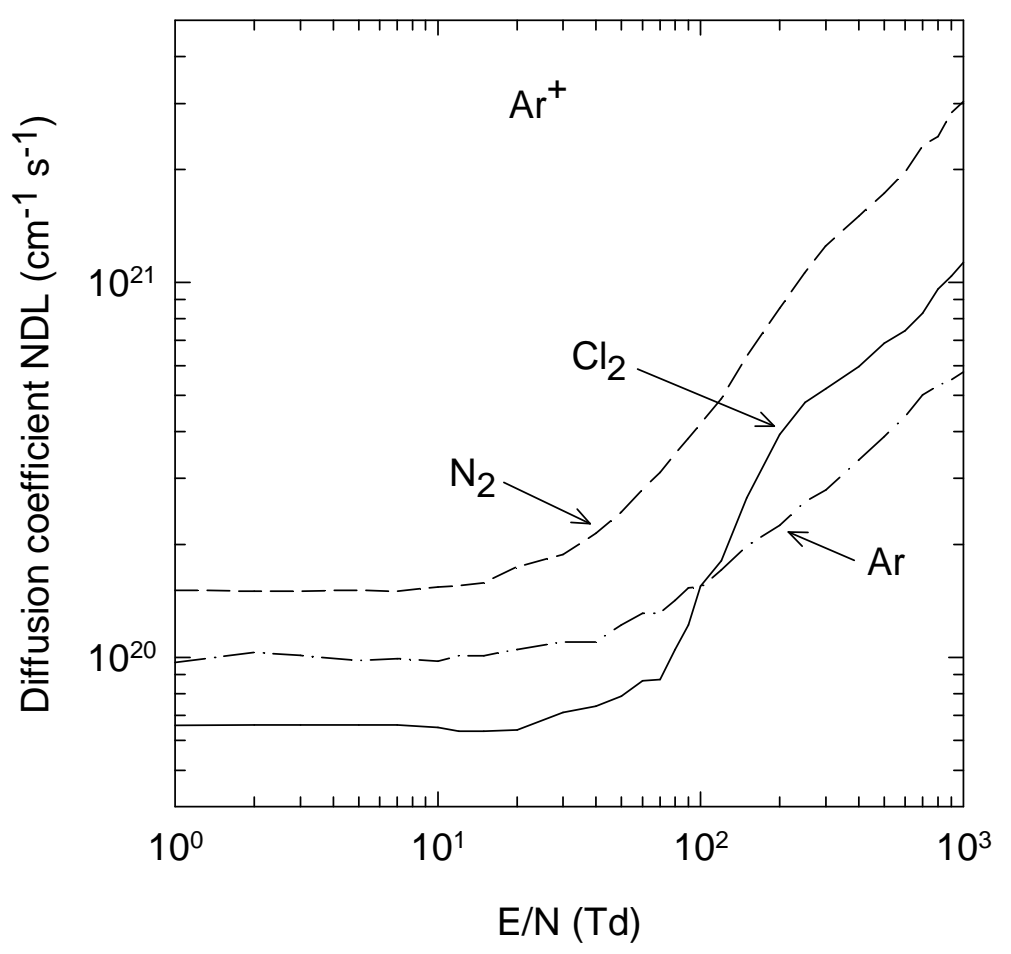

Figure 9: Longitudinal ion diffusion coefficient as a function of $\mathrm{E} / \mathrm{N}$ in the case of $\mathrm{Ar}^{+}$ interacting with pure $\mathrm{Ar}, \mathrm{Cl}_{2}$ and $\mathrm{N}_{2}$

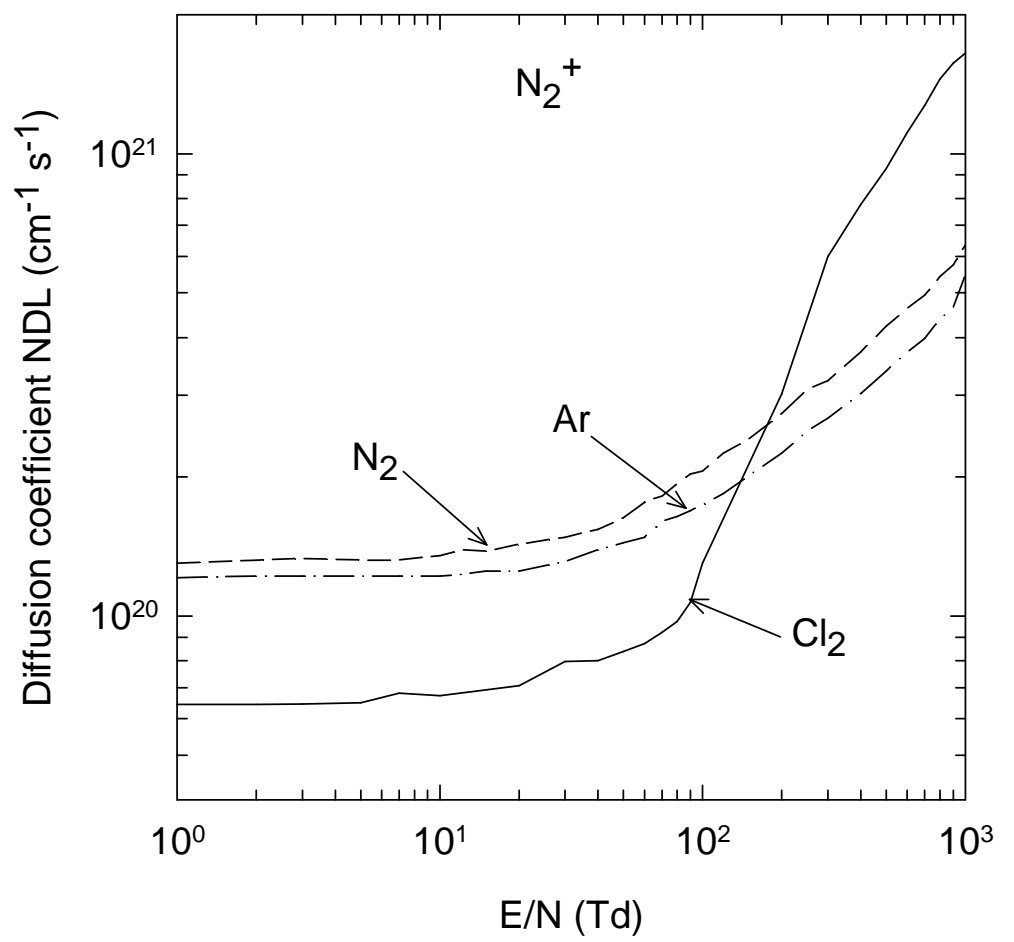

Figure 10: Longitudinal ion diffusion coefficient as a function of $\mathrm{E} / \mathrm{N}$ in the case of $\mathrm{N}_{2}{ }^{+}$ interacting with pure $\mathrm{Ar}, \mathrm{Cl}_{2}$ and $\mathrm{N}_{2}$ 


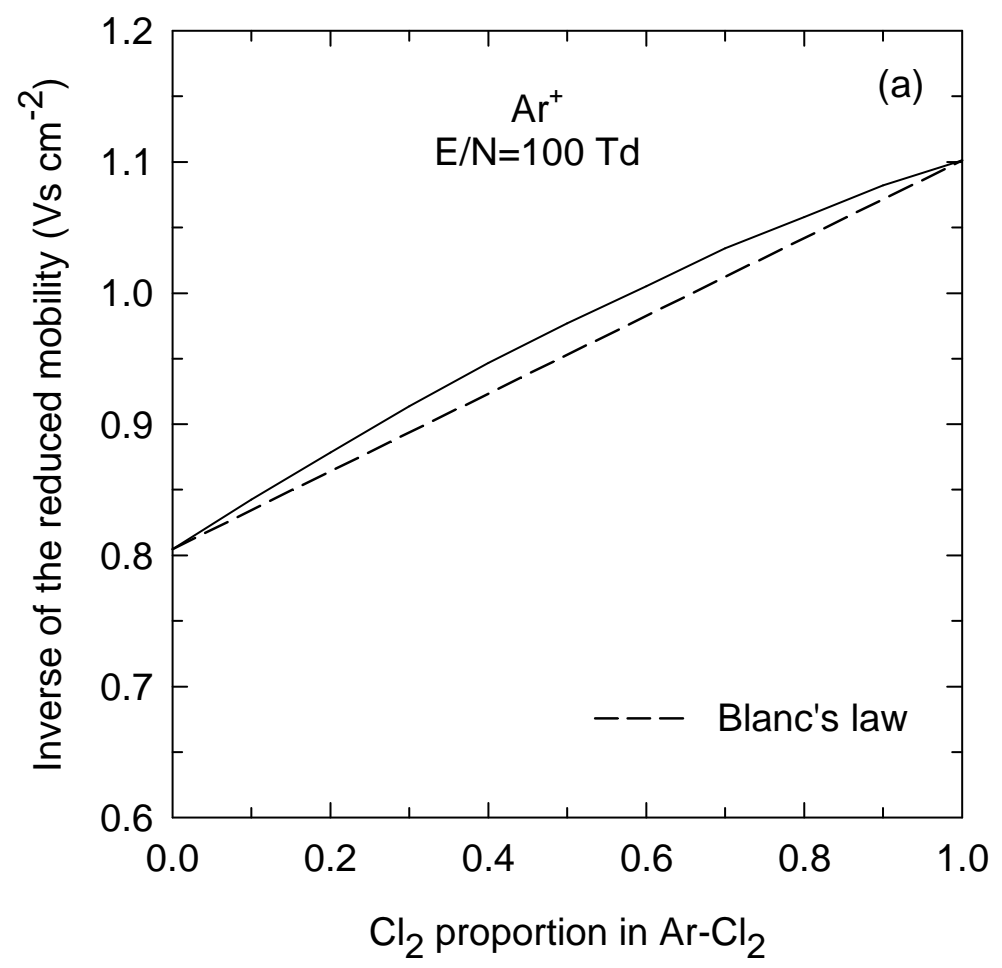

Figure 11a: The inverse of $\mathrm{Ar}^{+}$mobility in the $\mathrm{Ar}_{-}-\mathrm{Cl}_{2}$ mixtures as a function of the proportion of $\mathrm{Cl}_{2}$ at $100 \mathrm{Td}$. Monte Carlo calculations (Solid line) are compared to Blanc's law (Dashed line)

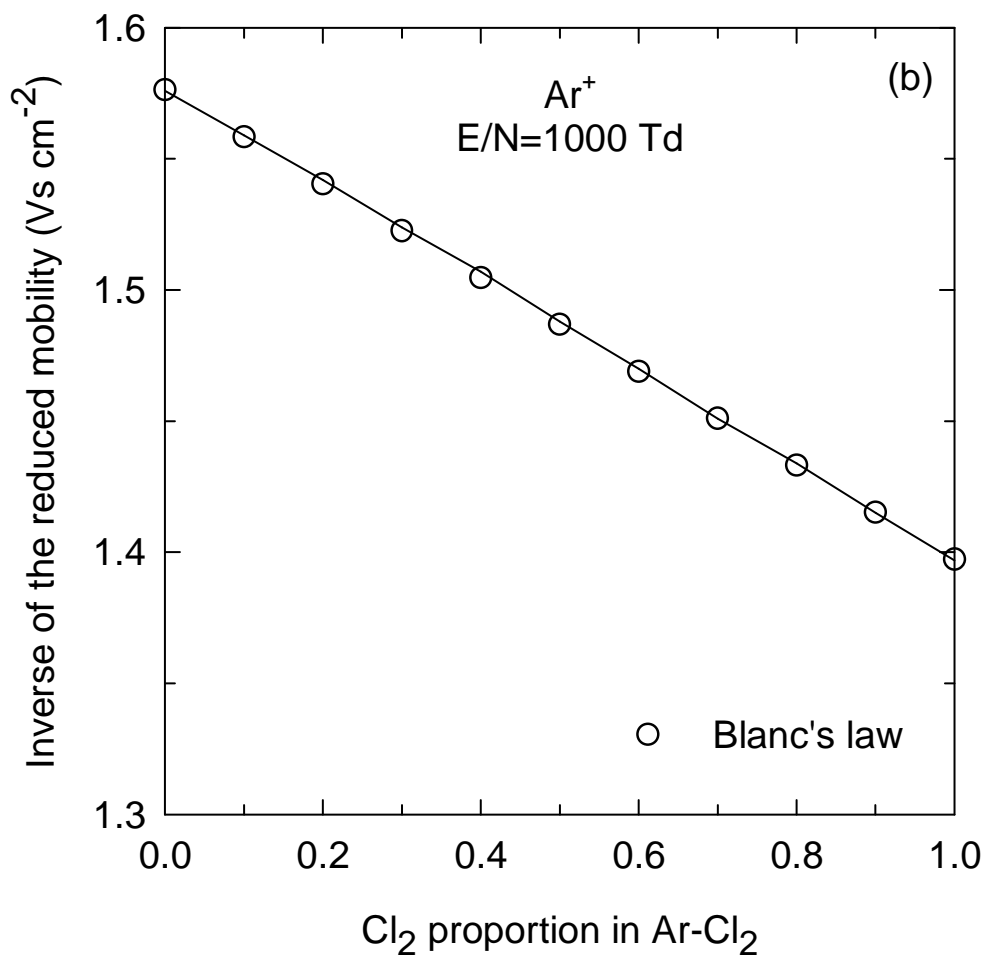

Figure 11b: The inverse of $\mathrm{Ar}^{+}$mobility in the $\mathrm{Ar}^{-} \mathrm{Cl}_{2}$ mixtures as a function of the proportion of $\mathrm{Cl}_{2}$ at $1000 \mathrm{Td}$. Monte Carlo calculations (Solid line) are compared to Blanc's law (symbols) 


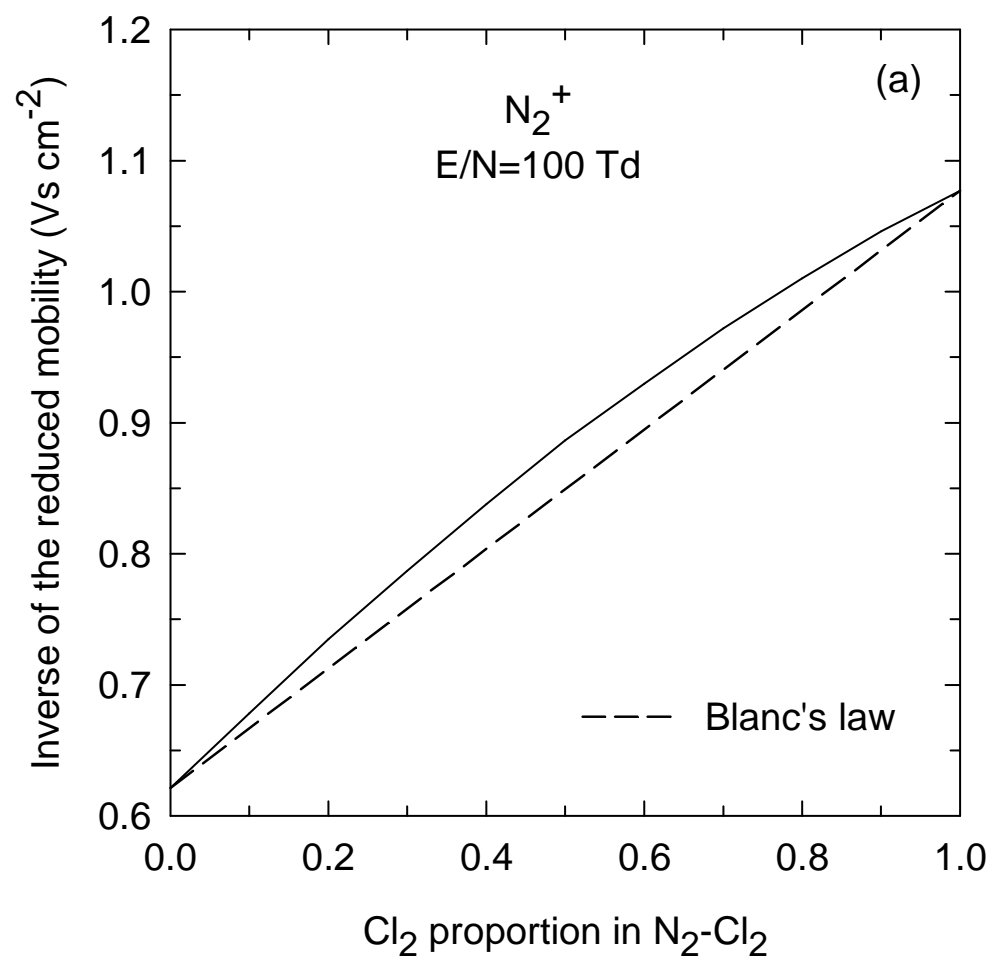

Figure 12a: The inverse of $\mathrm{N}_{2}{ }^{+}$mobility in the $\mathrm{N}_{2}-\mathrm{Cl}_{2}$ mixtures as a function of the proportion of $\mathrm{Cl}_{2}$ at $100 \mathrm{Td}$. Monte Carlo calculations (Solid line) are compared to Blanc's law (Dashed line)

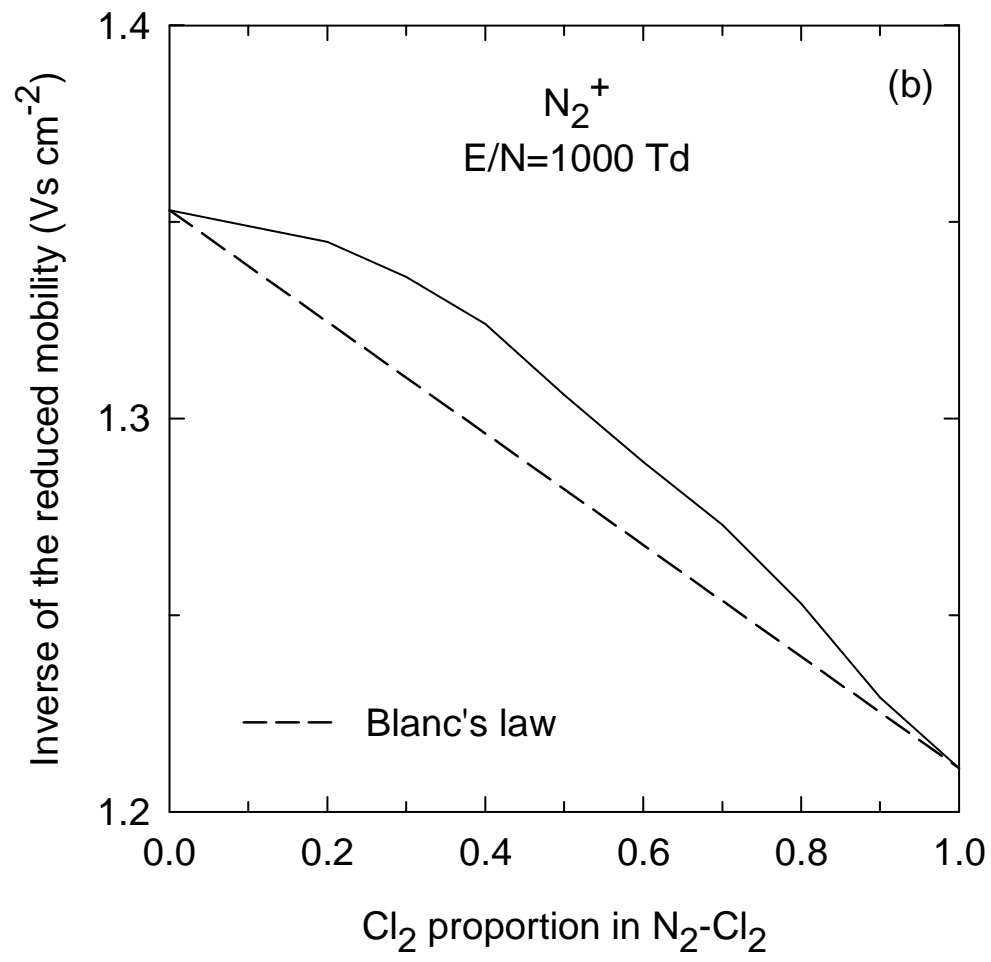

Figure 12b: The inverse of $\mathrm{N}_{2}{ }^{+}$mobility in the $\mathrm{N}_{2}-\mathrm{Cl}_{2}$ mixtures as a function of the proportion of $\mathrm{Cl}_{2}$ at $1000 \mathrm{Td}$. Monte Carlo calculations (Solid line) are compared to Blanc's law (Dashed line) 


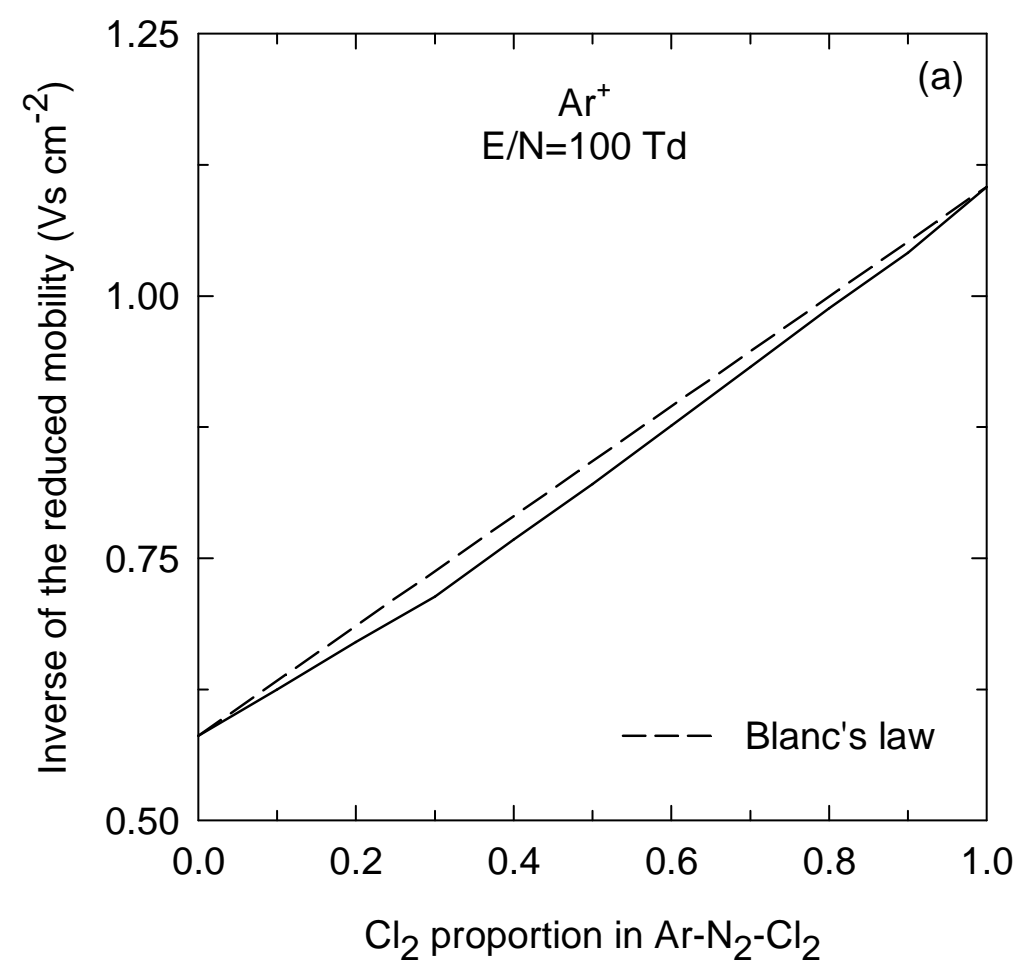

Figure 13a: The inverse of $\mathrm{Ar}^{+}$mobility in the $\mathrm{Ar}-\mathrm{N}_{2}-\mathrm{Cl}_{2}$ mixtures as a function of the proportion of $\mathrm{Cl}_{2}$ at $100 \mathrm{Td}$. Noting that $\mathrm{Ar}$ and $\mathrm{N}_{2}$ have the same proportion whatever the $\mathrm{Cl}_{2}$ proportion. Monte Carlo calculations (Solid line) are compared to Blanc's law (Dashed line).

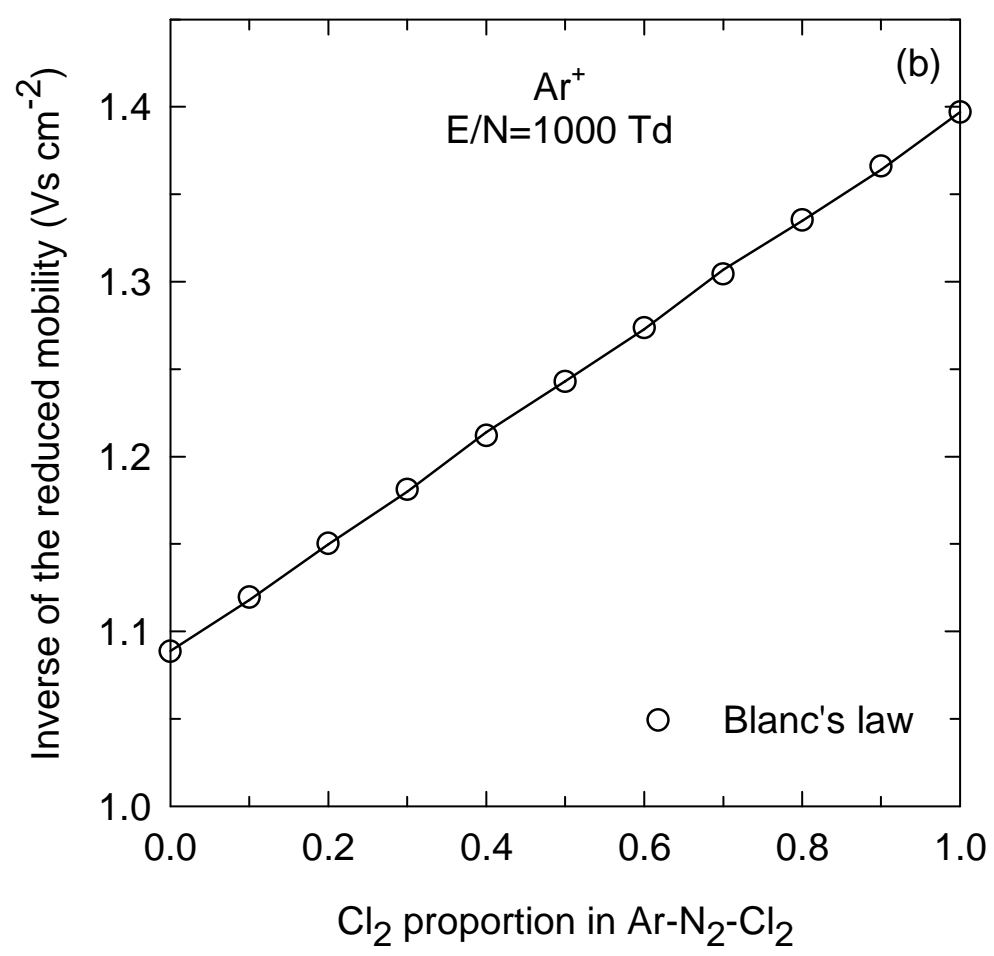

Figure 13b: The inverse of $\mathrm{Ar}^{+}$mobility in the $\mathrm{Ar}-\mathrm{N}_{2}-\mathrm{Cl}_{2}$ mixtures as a function of the proportion of $\mathrm{Cl}_{2}$ at $1000 \mathrm{Td}$. Noting that $\mathrm{Ar}$ and $\mathrm{N}_{2}$ have the same proportion whatever the $\mathrm{Cl}_{2}$ proportion. Monte Carlo calculations (Solid line) are compared to Blanc's law (Symbols) 


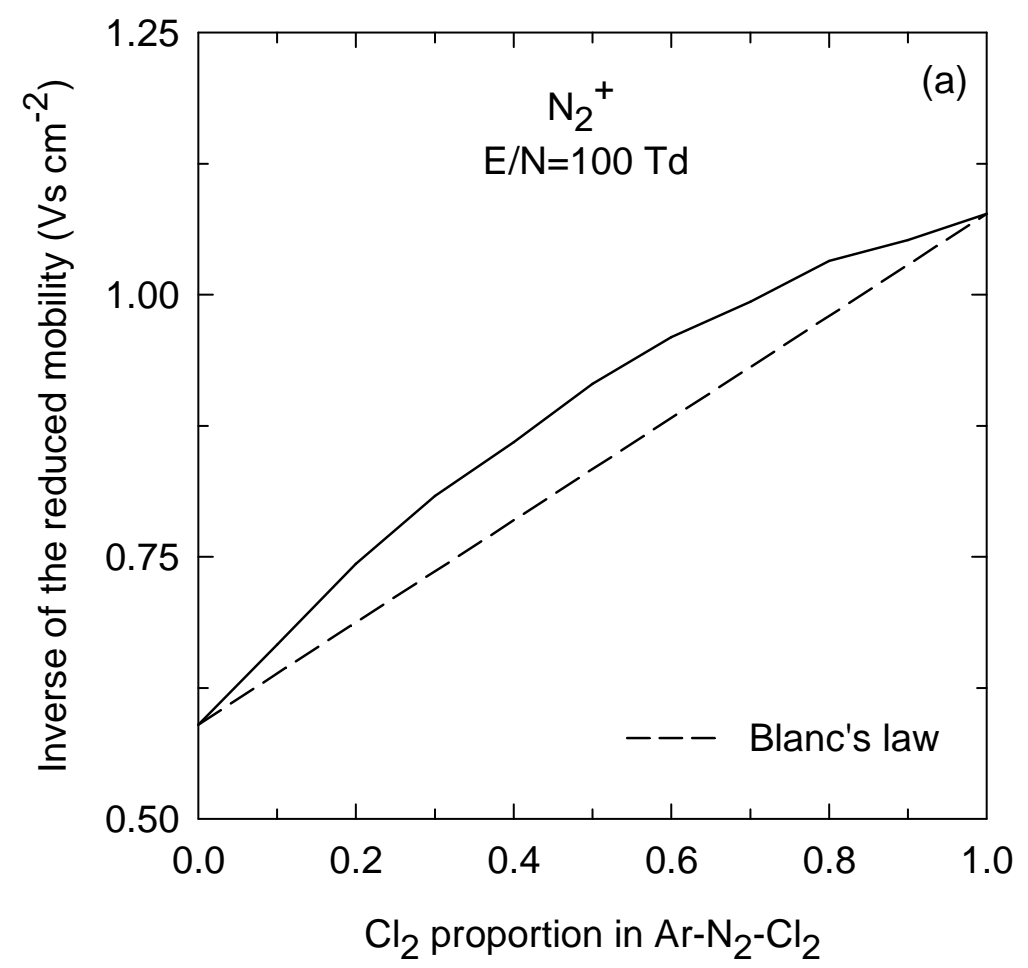

Figure 14a: The inverse of $\mathrm{N}_{2}{ }^{+}$mobility in the $\mathrm{Ar}-\mathrm{N}_{2}-\mathrm{Cl}_{2}$ mixtures as a function of the proportion of $\mathrm{Cl}_{2}$ at $100 \mathrm{Td}$. Noting that $\mathrm{Ar}$ and $\mathrm{N}_{2}$ have the same proportion whatever the $\mathrm{Cl}_{2}$ proportion. Monte Carlo calculations (Solid line) are compared to Blanc's law (Dashed line).

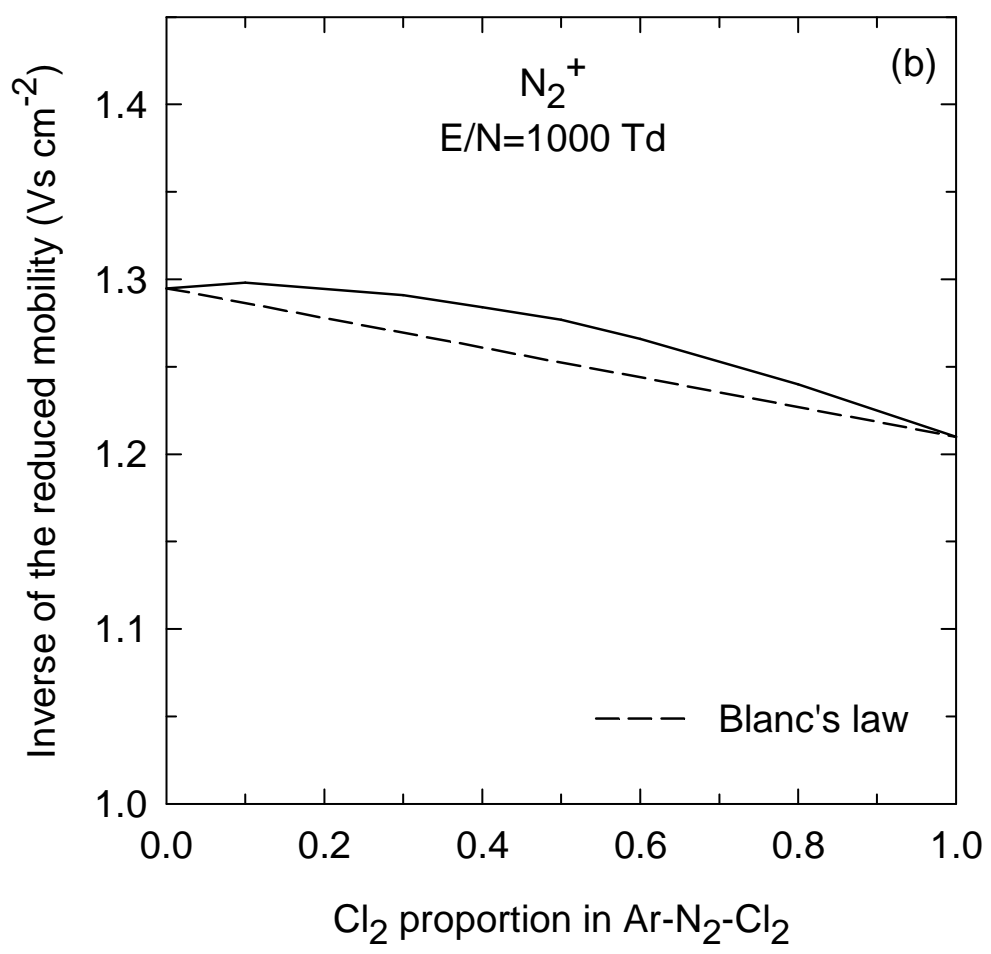

Figure 14b: The inverse of $\mathrm{N}_{2}^{+}$mobility in the $\mathrm{Ar}-\mathrm{N}_{2}-\mathrm{Cl}_{2}$ mixtures as a function of the proportion of $\mathrm{Cl}_{2}$ at $100 \mathrm{Td}$. Noting that $\mathrm{Ar}$ and $\mathrm{N}_{2}$ have the same proportion whatever the $\mathrm{Cl}_{2}$ proportion. Monte Carlo calculations (Solid line) are compared to Blanc's law (Dashed line). 